\title{
EL FEDERALISMO Y LA FISCALIDAD DEL ESTADO SOBERANO DE PANAMÁ, 1850-1886
}

Salomón Kalmanovitz*

Wn Colombia es muy desconocida la historia económica de $\mathrm{Pa}-$ hasta 1903, en parte porque era una provincia lejana de la capital, cuyas comunicaciones terrestres estaban, y aún están, interrumpidas por el tapón del Darién. Más importante quizás es que al renegar de la unidad nacional su historia se convirtió en un tema políticamente incorrecto. La mayor parte de las versiones locales de la pérdida de tan valioso territorio prefieren verla como una anexión violenta del imperio norteamericano, aunque existió una creciente insatisfacción de las élites panameñas por su desigual relación con Colombia. De 1903 en adelante, los colombianos no quisieron recordar que fue una parte muy dinámica de la sociedad política nacional durante el siglo XIX, la más liberal de sus provincias, y una de las más prósperas durante la segunda mitad de ese siglo.

Buena parte de la literatura escrita en Colombia se centra en la intervención de Estados Unidos para tomarse una franja de tierra fundamental para sus propósitos geopolíticos y económicos. Hay trabajos sobre la conexión entre el Este de Estados Unidos y el Oeste que experimentaba la "fiebre del oro", primero con un ferrocarril que

* Magíster en Economía, Decano de la Facultad de Ciencias Económicas y Administrativas de la Universidad Jorge Tadeo Lozano, Bogotá, Colombia, [salkal31@utadeo.edu.co]. Agradezco a la Universidad Jorge Tadeo Lozano por el financiamiento del proyecto "Las cuentas fiscales de los estados soberanos de Colombia, 1856-1886". Jorge Cuartas llevó a cabo la búsqueda y tabulación de los datos fiscales de manera eficiente. Edwin López, Miguel Urrutia y Alberto Supelano me hicieron comentarios oportunos. Alfredo Castillero me hizo conocer la bibliografía panameña. Rodolfo Segovia evitó que cayera en penosos errores y Tico Braun me cuestionó los contrafactuales. María Consuelo Moncada me prestó invaluable apoyo bibliográfico. Fecha de recepción: 26 de junio de 2012, fecha de modificación: 30 de agosto de 2012, fecha de aceptación: 16 de octubre de 2012. 
comenzó a funcionar plenamente en 1855 , el cuarto construido en el mundo (Poveda, 2004), y después con el canal, luego del fracaso de la iniciativa francesa. Los efectivos militares norteamericanos intervienen frecuentemente para proteger la ruta frente a levantamientos locales y las guerras civiles que se contagiaban al istmo, hechos que se prestan a la interpretación de que el Departamento de Panamá fue arrebatado por Estados Unidos (Santos, 2004; Lemaitre, 2003). Son pocos los trabajos de colombianos que subrayan la dinámica política para explicar la insatisfacción de Panamá con el centralismo que se impuso desde 1880 (Alarcón, 2010). Hinestrosa (2004) enfatiza la dinámica interna y los errores colombianos que produjeron la separación de Panamá en una presentación del libro de Cavelier (2003).

La literatura norteamericana se centra en la economía y en el costo-beneficio del canal para Panamá y para Estados Unidos (Maurer y Yu, 2011, que exponen una visión crítica de Estados Unidos) y en la política de la construcción del ferrocarril y de la vía interoceánica como gesta de un nuevo imperio (McCullough, 1977). Charles Bergquist (1981) hace un análisis que se basa en las razones políticas de Panamá para abandonar la República de Colombia, como el giro de La Regeneración hacia el centralismo, el sectarismo religioso y el proteccionismo. Por su parte, Fischer (1998) considera que la Guerra de los Mil Días fue la razón última de la separación de Panamá.

Entre los trabajos escritos por panameños hay buenas aproximaciones a la geografía y a la demografía (Jaén, 1979). La Historia general de Panamá, dirigida y editada por Alfredo Castillero (2004), es una obra exhaustiva que contempla la economía del istmo en el tiempo, y el análisis de la política, a cargo de Fernando Aparicio, muestra-igual que nosotros- que la separación del istmo fue provocada por el autoritarismo de La Regeneración. También se han escrito historias sobre el Panamá colonial y el Panamá colombiano (Araúz y Pizzurno, 1991 y 1993), que utilizamos junto con la obra de Castillero para ubicar el desarrollo de esta especial región del trópico en unas condiciones extremas que dificultaron su ocupación, su explotación económica y la construcción de las vías que terminaron por conectar el Pacífico con el Atlántico. Algunas visiones críticas, como la de Díaz Espino, postulan que Panamá fue un país inventado por el capital financiero norteamericano, postulado que cuestionamos pues encontramos una tradición nacionalista entre las élites panameñas (Arosemena, 1982) cuyos intereses contrapuestos y conflictos con la dirigencia colombiana se agudizaron con el proyecto de centralización política a ultranza de La Regeneración. 
Una de las hipótesis de este trabajo es que los intereses de Panamá se podían lograr relativamente bien en una organización política federal, como la que vivió Colombia a partir de 1853. Panamá contaba con un recurso geográfico privilegiado que aspiraba a explotar plenamente y, por tanto, debía recibir el apoyo de Bogotá para facilitar la construcción de sus infraestructuras, crear un orden político consensuado y permitirle una política de libre comercio para aprovechar su corredor entre los dos océanos. Todas estas premisas se cumplieron de manera imperfecta durante el auge del federalismo que se va estableciendo en el país desde el fin de la Guerra de Los Supremos. El estado soberano de Panamá disfrutará entonces de autonomía política y fiscal, se construirá el ferrocarril entre Ciudad de Panamá y Colón, se clausurará la aduana y habrá una convivencia entre el centro político de los Estados Unidos de Colombia y Panamá. Pero el debilitamiento del federalismo a partir de 1880 y su liquidación por la Constitución de 1886 son tendencias irreversibles que van empujando a las élites panameñas hacia su separación de Colombia.

Aunque en el lado colombiano se insiste en que la separación fue resultado del "destino manifiesto" de Estados Unidos (Santos, 2003), el canal se habría podido construir garantizando su neutralidad y el paso abierto a la pujante economía del imperio norteamericano, sin perder del todo la soberanía sobre tan vital territorio. La soberanía colombiana estaba subordinada al mantenimiento de la paz y el orden que las tropas y la armada norteamericanas estuvieron prestas a ejercer en varias ocasiones ante la debilidad del estado nacional. De hecho, el Estado colombiano no logró consolidar un orden político sólido y consensuado que le permitiera asumir el monopolio de los medios de violencia, y ello pesará en el futuro del istmo, por la misma razón: no podrá defender la soberanía sobre todo su territorio. Todo lo anterior permitirá que los Estados Unidos ejerzan una soberanía de hecho para defender el ferrocarril construido con sus capitales en situaciones de guerras civiles o de protestas populares contra el ejercicio abusivo de la autoridad por las tropas norteamericanas o sus ciudadanos. La decisión de construir el canal interoceánico por el gobierno de Estados Unidos se tomó intentando lograr primero un consenso con Colombia a comienzos del siglo XX, pero la posición cerrada del gobierno conservador contra el tratado llevó a rechazarlo irrevocablemente. Esta fue la gota que rebosó la copa y llevó a la separación del Departamento de Panamá para convertirse en nación, más interesada en la construcción rápida del canal interoceánico que la paramuna élite colombiana. 
Este trabajo intenta entender cómo se desenvolvieron las relaciones entre el centro político y una periferia lejana, desde el punto de vista de los intereses tanto de las élites panameñas como de las colombianas. Se ocupa de la política en Panamá y de su evolución fiscal cuando era parte integral de los Estados Unidos de Colombia. Sus objetivos son varios: fuera de analizar la evolución económica y fiscal del istmo en sí misma, explora las tensiones entre el gobierno central y el federalismo, que debieron multiplicarse con la centralización conservadora emprendida después de 1880.

El ensayo está ordenado en la forma siguiente: revisa el nacionalismo panameño derivado del papel que jugaba su élite en el comercio con el Caribe, Ecuador y Perú, y entre el Pacífico y el Atlántico; el análisis de la demografía y la geografía de Panamá muestra sus grandes diferencias con el resto del territorio colombiano; la construcción del ferrocarril cambió su fisonomía económica y fue clave en el papel que desempeñaría en el comercio global; reseña brevemente las condiciones políticas de Panamá, en especial la apertura democrática que produjo la Constitución de Rionegro y permitió la participación popular en la política local, aunque la inestabilidad política fue una excusa para que Rafael Núñez demonizara el federalismo; después se examinan las cuentas fiscales del estado soberano -ingresos, gastos, déficit y deuda pública- y las finanzas de la capital, que muestran un aumento del gasto en educación; terminamos con un epílogo que describe la economía y las cuentas públicas del Departamento de Panamá.

\section{EL NACIONALISMO PANAMEÑO}

La lucha de las regiones que conformaron la República de la Nueva Granada por autonomía y recursos fiscales se expresó de la manera más clara en las conflictivas relaciones entre Panamá y Bogotá, aunque portavoces de otras regiones como Bolívar, Antioquia y Tolima también amenazaron con abandonar la Unión en algunas ocasiones.

En teoría, la pugna entre unas regiones y un centro político versa sobre las ventajas que les reporta su participación en una unión política, en términos del poder militar y económico central que garantiza su seguridad y, al tiempo, el desarrollo económico y las infraestructuras requeridas. Un atractivo adicional es la existencia de un mercado interno para vender la producción de cada una de las regiones que lo integran. Por su parte, la fortaleza de la región reside en su capacidad de renegar de la unión y asumir su independencia cuando su potencial de desarrollo depende más de ella misma que de su relación con el 
centro (Martínez, 2011). En el caso de Panamá, su potencial como paso interoceánico era enorme y su relación con otros países poderosos podía garantizarle un futuro más próspero que el que of recía Colombia, que operaba como un molesto intermediario.

Existen siempre incentivos económicos y amenazas de conflicto en los acuerdos fiscales de un sistema federal. Los acuerdos políticos dan lugar a decisiones estratégicas que buscan beneficios económicos para los estados afiliados y la federación que los asocia. Sus estrategias y planteamientos están limitados por el poder económico de cada cual y por la credibilidad de las amenazas de secesión de cada región. Así, aunque estados como Bolívar o Antioquia también amenazaron con retirarse de Colombia, solo Panamá tenía un poder económico suficiente para lograrlo, aunque condicionado por la gran inversión para construir el canal interoceánico. Colombia no era capaz de emprender por sí misma la construcción de un ferrocarril, y menos de un canal, por obvias razones. La amenaza panameña de separación no fue tomada en serio por el partido conservador, que precipitó así la pérdida de tan vital territorio en 1903.

Panamá era la provincia de mayor valor geográfico entre las que formaban la República y siempre lo tuvo en cuenta para negociar su anexión al centro político, ya fuese en 1830 al final de la dictadura de Bolívar, en 1840 cuando se retiró de la República Granadina o en 1841 cuando se reintegró a condición de que el incipiente país se constituyera como un Estado Federal; incluso algunos constituyentes propusieron en 1863 que Ciudad de Panamá fuera la capital de los Estados Unidos de Colombia (Alarcón, 2010, 187) para que se asociara más estrechamente a la Nación y esta mirara hacia el globo.

En 1840 los istmeños decidieron retirarse de la República en medio de la Guerra de Los Supremos, de cuyo desenlace temían que surgiera una dictadura centralista, y retornaron a la unión un año más tarde cuando ese proyecto fue derrotado, convencidos de que se impondrían las ideas liberales y conociendo que otras élites regionales compartían su aspiración federalista. Efectivamente, en 1855 se conformaron como estado soberano, estrenando el ferrocarril que construyeron los norteamericanos con base en un contrato firmado con el gobierno nacional.

El primer presidente del estado soberano de Panamá, Justo Arosemena, al posesionarse en 1855 dijo en su discurso inaugural:

Una nueva era se abre para nuestro país en el libro misterioso del tiempo. El Congreso de la Nueva Granada, por un acto verdaderamente magnánimo, ha reconocido pacífica, voluntaria y desinteresadamente la soberanía del país en que hemos nacido. Se le representó nuestro derecho, hablósele en nombre de 
la libertad de los pueblos, palpó las exigencias de nuestra singular posición [...] [y consideró] que esos títulos eran más que suficientes porque eran incontestables (Arosemena, 1984, 83).

Y agregó:

¿Quiere decir que la Nación tiende a dividirse, y que perderá en fuerza y en respetabilidad exterior lo que gane en adelanto y prosperidad doméstica? No por cierto. La mejora interna que produce necesariamente un gobierno obrando sobre un territorio pequeño, homogéneo y perfectamente conocido, no se reduce a un adelanto puramente local, puesto que la Nación no es otra cosa que el conjunto de sus localidades. ¿Y cómo puede concebirse prosperidad de las partes y del todo, sin aumento de fuerzas parciales y totales? (ibíd, 86).

El liberalismo que se acendró en Panamá tenía que ver con su oligarquía comercial que mantenía lazos con las Antillas inglesas y holandesas y con los puertos del Pacífico y del Atlántico, más que con la enclaustrada Bogotá. Esa posición estaba en franca contradicción con el centralismo autoritario que fuera el pilar fundamental de la doctrina conservadora; de esta, las políticas proteccionistas y de monopolio religioso repugnaban en especial a la élite comercial panameña, cuyos intereses requerían del librecambio y de la libertad tanto económica como religiosa. En efecto, la construcción del ferrocarril y el mismo canal interoceánico eran proyectos fundamentales para el desarrollo del comercio panameño e implicaban una gran movilidad de una población cosmopolita que incluía chinos, jamaiquinos, norteamericanos e ingleses, que practicaban muchos credos y se asentaban temporal o permanentemente en las ciudades principales del istmo para encauzar el comercio y los servicios que se desprendían de su vocación geográfica. Para los liberales panameños no tenían sentido las normas católicas que regulaban la vida civil de las personas, el matrimonio y la prohibición del divorcio, y que negaban el derecho a una educación laica u orientada por otra religión y el acceso a cementerios plurirreligiosos ${ }^{1}$, entre otros.

La protección, por otra parte, es una forma de entrabar el comercio internacional, imponiéndole aranceles a la importación de mercancías que reducen la rentabilidad del negocio y la extensión del mercado, más aún en Panamá que operaba como punto de trasbordo del tráfico que se dirigía a otros países. Por eso, la élite comercial panameña había demandado desde siempre que no hubiera aduana en el istmo, prerrogativa que le fue concedida en 1849.

De acuerdo con Martínez Garnica, la actividad intelectual de los dirigentes panameños era muy intensa y contribuyó al ideario del liberalismo y del federalismo. "Cinco reformas políticas adoptadas a

\footnotetext{
${ }^{1}$ En 1833, por ejemplo, una ley permitió establecer cementerios para extranjeros no católicos, lo que indica que hasta entonces estaban prohibidos.
} 
mediados del siglo XIX llevan la impronta de la acción de los políticos istmeños: la adopción del régimen federal y de la postura librecambista, la institucionalización de los jurados de conciencia y la adopción del principio habeas corpus, la introducción del matrimonio y el divorcio civil, con una igualación de los hijos naturales reconocidos respecto de los legítimos, y la reducción del ejército permanente" (Martínez, 2004). Todo esto fue suprimido por La Regeneración que erigió una organización política muy centralizada, dio cierta protección a los artesanos del centro del país que los panameños consideraron un despropósito, eliminó la participación ciudadana en el sistema judicial y el sufragio universal, introdujo elecciones indirectas y vulneró sistemáticamente la libertad de prensa y el habeas corpus.

El nacionalismo panameño se va forjando por la escasa coincidencia de intereses económicos y políticos con el poder central, sobre todo en las fases de conservadurismo con su pretensión de concentrar el poder político en la capital. Hubo conatos separatistas en 1840, en 1856 y en 1870, y la fatiga de los dirigentes panameños aumentó con la hegemonía que estableció La Regeneración y sobre todo, con la Constitución de 1886, con el acendrado centralismo y el dogmatismo religioso. La elección de Rafael Núñez a la presidencia en 1880 inició una larga hegemonía conservadora que con variantes importantes se prolongó hasta 1930.

Los conservadores colombianos temían a Estados Unidos no solo por su amenazante vigor económico y militar sino también porque era un Estado laico donde proliferaban las iglesias protestantes, muchas de ellas proselitistas, que podían desafiar el hegemonismo católico. Para los panameños, los norteamericanos construyeron el ferrocarril que unía a Ciudad de Panamá con Colón y podían ser los forjadores del canal interoceánico que vislumbraban como la redención económica de su región, a pesar de que también resentían la arrogancia imperial con sus imposiciones sobre la administración del ferrocarril y la defensa a ultranza de sus intereses, algo que sabían se repetiría a una escala superior el día que construyeran el paso entre los dos océanos.

No obstante, el espectro político de Panamá no era uniformemente liberal: las provincias del interior estaban dominadas por élites ganaderas muy conservadoras que se entrelazaban con sus copartidarios colombianos para oponerse a los gobiernos liberales del estado soberano, siendo una de las fuentes de la inestabilidad que azotaba la política panameña. Estas también defenderían la herencia hispánica y católica, y rechazarían las pretensiones imperiales de Estados Unidos por el control territorial sobre cualquiera que fuera el brazo que co- 
municara el Pacífico con el Atlántico. Así, el frecuente conflicto civil colombiano se transmitía a Panamá, aunque solo en la Guerra de los Mil Días se tornó en teatro principal de la conflagración.

En 1863 la Constitución de Rionegro reorganizó las relaciones entre los estados y el centro político de los nuevos Estados Unidos de Colombia, otorgando soberanía a las regiones en asuntos políticos, judiciales y fiscales. Esto mantuvo la adhesión de Panamá a los Estados Unidos de Colombia, aunque los anhelos de prosperidad comenzaban a frustrarse con la pérdida de la ventaja competitiva del ferrocarril istmeño frente al ferrocarril transatlántico de Estados Unidos terminado en 1869. La adopción del sufragio universal democratizó la política local y las frecuentes movilizaciones populares lograron que se les tuviera en cuenta en el gasto público. Los intereses norteamericanos cobraron una influencia creciente en la política del istmo, especialmente desde 1865, cuando desembarcaron tropas y favorecieron la caída del presidente del Estado, José Leonardo Calancha; así, cada vez que una guerra civil sacudía a Colombia y ponía en riesgo la seguridad del transporte de mercancías y pasajeros entre Ciudad de Panamá y Colón, los norteamericanos acercaban su flota al istmo o desembarcaban tropas.

El balance que debieron hacer las élites panameñas sobre Colombia tuvo que ser bastante negativo. En el siglo XIX no se consolidó un Estado nacional que garantizara el orden político y, por el contrario, era interrumpido por las frecuentes guerras civiles; aunque el proceso de centralización avanzó después de la separación de la Iglesia y el Estado, el poder político y militar del ejecutivo fue limitado por la Constitución de Rionegro, y las élites regionales se alzaban a menudo contra el gobierno central o luchaban contra los partidos contrarios a sus intereses. La centralización autoritaria de Núñez y Caro causó disensiones e impidió el fortalecimiento económico del Estado, ya que era difícil establecer una tributación consensuada. El mercado interno estaba fragmentado por la escarpada geografía y por las relaciones sociales semifeudales; las regiones costeras, con las que Panamá podía intercambiar sus productos, eran especialmente pobres y atrasadas. Durante el siglo XIX, esa pobreza crónica determinó que el gasto público dedicado al desarrollo regional fuera precario, si no inexistente. Por último, la alianza con capitales de Francia para construir el canal interoceánico naufragó técnica y financieramente, provocando en la élite panameña un profundo pesimismo en torno a su futuro.

En términos contrafactuales, Panamá habría permanecido en la órbita nacional si el gobierno central le hubiera garantizado autono- 
mía política y fiscal, estabilidad política, reglas de juego apropiadas y predecibles para encauzar distintos intereses, paz y capacidad para construir las vías que materializaran su enorme potencial como avenida comercial entre el Pacífico y el Atlántico, punto neurálgico de las comunicaciones globales. Al mismo tiempo, Bogotá tendría que haberle permitido apropiarse de una mayor parte de los recursos fiscales que podía generar con su riqueza, y haberle hecho transferencias que apoyaran su desarrollo, en vez de que fuera tributaria de Colombia como evidentemente lo fue. Seguramente Estados Unidos hubiera atropellado la soberanía colombiana de no haberse dado la separación.

En 1886, una constitución centralista le quitó a Panamá (y a las demás regiones) todas sus prerrogativas de autonomía política y le restó recursos presupuestales a los estados soberanos, convirtiéndolos en departamentos, entes atrofiados con muy pocos recursos fiscales a los que despojó de toda autodeterminación. Núñez adujo que la anarquía que trajo el federalismo tenía su epítome en Panamá con sus frecuentes cambios de mandatarios, y los que con la nueva constitución entraron a ser nombrados directamente por Bogotá, en su mayoría no eran siquiera oriundos del istmo. En tiempos del federalismo $\mathrm{Pa}-$ namá envió como delegados a las deliberaciones de la Constitución de 1855 y de 1863 a sus más distinguidos portavoces e intelectuales, como Justo Arosemena. En cambio,

los delegatarios de esa región a las deliberaciones de la Constitución de 1886 fueron escogidos a dedo por el gobierno y resultaron ser sus voceros Miguel Antonio Caro, quien no conocía el mar, ni el río Magdalena y menos aun Panamá; y el otro lo fue Felipe Fermín Paul [...] hermano de monseñor José Telésforo Paul, arzobispo de Bogotá durante la Regeneración y gran amigo de Núñez (Alarcón, 2010, 211).

Para rematar, la exclusión política quedó constitucionalizada en el artículo 201 que afirmaba: "el Departamento de Panamá está sometido a la autoridad directa del Gobierno, y será administrado con arreglo a leyes especiales" (ibíd., 214). Es grande la clarividencia de José María Samper, el único intelectual ex liberal que fue delegado en la Constituyente de 1886, aunque al mismo tiempo muestra gran torpeza política al defender el estatus especial impuesto a Panamá:

E1 istmo de Panamá es realmente una especie de territorio anseático; por su posición interoceánica; por su estructura topográfica; por la composición heterogénea y cosmopolita de su población; por su alejamiento del centro de la república; por los graves intereses internacionales que allí se aglomeran o comprometen, por las vías que existen y el gran Canal que se está excavando para el tráfico del mundo entero; por la amplia franquicia que favorece el tránsito y a las importaciones y exportaciones; por el interés de la soberanía nacional y del equilibrio comercial y marítimo entre las naciones europeas y americanas y sus grandes Colonias de la Oceanía; por la naturaleza de las 
transacciones que se celebran, con moneda y mercancías de todos los países; y por otras circunstancias importantes, el Departamento de Panamá necesita ser administrado conforme a reglas muy especiales (ibíd., 215).

Cada una de las razones de Samper requería asegurar la lealtad de los dirigentes y ciudadanos panameños con el centro político. Pero los conservadores les impusieron su visión autoritaria y religiosa; sus políticas eran contraproducentes e inexorables y negaban sus intereses fundamentales. Entre otros, la aduana en Panamá, abolida en 1849, se restableció en 1886 y entorpeció su desarrollo comercial. Al mismo tiempo, la construcción del canal, contratado con el conde Ferdinand Lesseps, que se inició a principios de 1882 y suspendió obras en mayo de 1889, desmoronó la ilusión de los panameños.

Luego de un gasto de más de 400 millones de dólares y cuando apenas se habían terminado menos de dos quintas partes del canal, la primera Panamá Canal Company, las aspiraciones de Colombia de asumir un papel más prominente en el liderazgo hemisférico y la reputación de Ferdinand Lesseps se desplomaron con la quiebra económica de la compañía (Randall, 1992, 87).

Un periódico panameño se expresó así sobre la situación ocasionada por la cancelación de las obras:

Ha llegado una época de verdadera crisis para el istmo, época temida hace tiempo aún por los más escépticos en materia de esperanzas, ya que la situación financiera del país se hace cada vez más tirante, más amenazadora, por la ruina de las masas, principalmente, que entraña un largo catálogo de desdichas. Se ha repetido hasta la saciedad que aquí se carece de vida propia, que dependemos en lo absoluto de circunstancias transitorias y excepcionales, que nuestra existencia comercial o financieramente hablando, es del todo falsa, por lo efímero (citado por Araúz y Pizzurno, 1993, 204).

A la constitución impuesta en 1886 la siguieron varias guerras civiles que en Panamá se expresaron con fiereza especial durante la Guerra de los Mil Días, que terminó en 1902 y dejó exangüe al país.

El istmo, que nunca participó en las luctuosas guerras civiles colombianas, se estrena como el teatro de las más sangrientas batallas. Todo el departamento toma las armas bajo los pendones del partido liberal. Cuando, en Colombia el liberalismo claudica, sus fuerzas aún dominan Panamá (Figueroa, 1978, 352).

Debió haber producido una enorme frustración a la dirigencia panameña que los conservadores ganaran esta guerra y vislumbraran su hegemonía interminable.

Para rematar, en 1903 Colombia rechazó el tratado Herrán-Hay por el cual los norteamericanos ofrecían una indemnización de 10 millones de dólares y un pago posterior de US $\$ 250.000$ anuales al gobierno, a cambio de los activos de la fracasada aventura del conde Ferdinand Lesseps, y se comprometían a construir el anhelado canal, tratado que los panameños consideraban de suma conveniencia para 
sus intereses. Pero el Senado colombiano, controlado por Miguel Antonio Caro, rechazó de manera unánime e irrevocable la propuesta, ante la desilusión de los istmeños. Todas estas circunstancias acentuaron las tensiones entre la dirigencia de Panamá y la de Bogotá y llevaron a que Panamá se independizara de Colombia, de la mano de Estados Unidos, y se convirtiera en Estado independiente, aunque muy sometido a los norteamericanos.

La liquidación del federalismo por los conservadores también socavó el modus vivendi entre Panamá y Colombia. El triunfo del centralismo fue lamentado profundamente por su dirigencia política y sustentó las aspiraciones separatistas que se concretaron en 1903, también bajo la presión norteamericana que había fracasado en sus negociaciones con Colombia para construir el canal. El conflicto entre federalismo y centralismo le permitió al imperio anexar la zona del futuro canal con el beneplácito de la mayoría de las élites panameñas y sin necesidad de violencia. También lo hizo en condiciones mucho más desventajosas de las que contemplaba el tratado Herrán-Hay.

\section{LA DEMOGRAFÍA Y LA GEOGRAFÍA DE PANAMÁ}

Durante la Colonia, Panamá fue paso obligado de la plata que venía de Potosí a cambio de las vituallas que se enviaban de España. En la travesía se usaban esclavos que vadeaban trochas imposibles. Más adelante, la carga creció y se movilizaba por estrechos caminos de mulas y puntos de acopio sobre las dos costas; se podría decir que entonces el istmo era relativamente próspero. Las ferias de Portobelo se reunían una vez al año y a ellas afluían comerciantes de Jamaica, Curazao, Guayaquil, El Callao y Cartagena. Pero esta ruta era vulnerable y se suspendió en 1739 con el ataque del pirata Edward Vernon a Portobelo y Chagres, mientras que los asientos de esclavos concedidos a Inglaterra y Francia le hacían competencia al tráfico humano español a cambio de metales preciosos (Araúz y Pizzurno, 1991, 64). Con el poblamiento del Cono Sur y el papel que jugó como despensa de la minería de Potosí, las flotas españolas abrieron la ruta por Buenos Aires y pasaban por el Cabo de Hornos para recoger la plata en El Callao, de modo que Panamá entró en un largo letargo económico que en verdad no terminó hasta que se desató la fiebre del oro de California. Según Castillero:

En la segunda mitad del siglo XVIII el panorama comercial de Panamá era desolador. Apenas llegaban barcos por el Pacífico o el Caribe. El país no tenía nada valioso que exportar, salvo la plata que le entraba con el situado, y esclavos. De hecho son esclavos la única mercancía de salida en numerosos embarques, y es probable que los barcos que llegaban de 
Perú, del Ecuador, o de las costas del Pacífico neogranadino, lo hacían para comprar solo esclavos, llevando como carga a Panamá, productos alimenticios, o bien productos como el cacao (aunque cada vez menos), quinina, y lana vicuña, siempre en pequeñas cantidades y casi todo para reexportar (Castillero, 2005, 12).

Una vez destruido el sistema colonial español, continuó el deterioro de la economía panameña porque la minería decayó por doquier; se suspendió el comercio con la metrópoli, sin que surgiera un mercado global hasta mediados del siglo XIX; los abastos cambiaron de procedencia, y el comercio que fluía por el istmo se redujo al mínimo. "La decadencia económica constituyó una de las características más notables de las tres primeras décadas que siguieron a la independencia de Panamá y la inmediata unión voluntaria a la República de Colombia, en 1821" (Araúz y Pizzurno, 1993, 247). En 1827, el comandante del istmo afirmaba: "el comercio se encuentra en la última languidez: algunos botes de cabotaje y uno que otro barco de Guayaquil y Jamaica son los únicos que se presentan en estos mares [...] La agricultura está en su infancia y solo se sostiene con algún lustre la de legumbres y menestras" (ibíd., 248). De 1830 a 1840 se exportaron en promedio $\$ 60.000$ en bienes producidos localmente, que hacia 1850 se multiplicaron por 5 y en 1864 llegaron a $\$ 580.000$ (Castillero, 2005). Durante las luchas por la Independencia,
la plata del Alto y Bajo Perú (Oruro, Pasco, Potosí, y otras minas), que antes tenía su salida por Buenos Aires o por el Cabo de Hornos, empezó a tomar el rumbo de Panamá al estallar la insurgencia en Argentina y Chile, lo que hacía muy inseguro el transporte por estos territorios o frente a sus costas [...] Jamás había ocurrido nada semejante en la historia del comercio pa- nameño. Era una verdadera epifanía que hacía recordar los tiempos dorados de las ferias opulentas [...] En cuanto al comercio con Perú, hasta ahora mucho menos estudiado o documentado, se sabe eso sí que la fortuna de los hermanos Mariano, Blas y Juan Arosemena se originó en esta etapa de auge comercial, gracias a sus negocios con Lima (ibíd.).

En 1836 el tráfico algo se había recuperado pero seguía siendo de transbordo: incluía exportaciones domésticas de carne, cueros, sebos velas, jabón, carey, nácar, perlas, tablones y zarzaparrilla, por $\$ 60.450$. Aunque la recuperación no era completa, el viajero inglés P. Campbell Scarlett observó que la mayoría de los nativos se ocupaba del comercio extranjero. $Y$ también que el Camino de Cruces estaba en condiciones desastrosas, con huecos profundos donde resbalaban los caballos en época de lluvias, y que no valía la pena repararlo. No había una organización política que destinara recursos a mantener la vía en buen estado, con lo cual habría aumentado el tráfico de la vía más conveniente para unir los dos océanos. 
En 1838 el cónsul inglés anotó que las residencias y bodegas de los antiguos comerciantes de Ciudad de Panamá estaban en ruinas y otras se habían dividido en pequeños apartamentos y

han sido dejados a las clases más necesitadas, las cuales están en un estado
de desocupación y abandono, tal como solo se encuentran en los climas
tropicales donde las necesidades vitales son pocas y se produce con poca
laboriosidad [...] las ruinas de las iglesias y otros grandes establecimientos
públicos, cubiertos de monte y las calles llenas de hierba, dan al pueblo la
apariencia de haberse expuesto a los estragos de la guerra, pero era el efecto
de la decadencia.

Se observaba al mismo tiempo una gran dificultad para enganchar obreros, tanto de la región como de áreas vecinas, debido a las relaciones de servidumbre en el interior del istmo.

Cuadro 1

Población del istmo de Panamá según estamentos, 1778

\begin{tabular}{lrc}
\hline & Número & Porcentaje \\
\hline Blancos & 9.064 & 15,1 \\
Libres de todos los colores & 33.377 & 55,6 \\
Indios & 13.869 & 23,1 \\
Esclavos & 3.474 & 5,8 \\
Religiosos & 260 & 0,4 \\
Total & 60.044 & 100,0 \\
\hline
\end{tabular}

Fuente: Jaén (1979, 394).

La población de Panamá en 1778 era de unos 60.000 habitantes, sin contar unos 15.000 indígenas; clasificados por estamentos, el censo informa que los "libres de todos los colores" son la mayoría, un 55,6\%; los "blancos" suman el 15,1\%, o sea que los dos grupos llegan al 70,7\%, cifra parecida a la de la Nueva Granada. Se trata entonces de una población altamente mestiza o hispanizada. Los indígenas censados constituyen el $23,1 \%$ de la población y los esclavos el 5,8\%. Solo hay 260 religiosos, lo que da una atención de 2.300 personas por clérigo (o monja) y sugiere un alto grado de paganismo entre la población.

La población ocupa un territorio amplio con una densidad muy baja, 1 hab. $/ \mathrm{km}^{2}$, que impide explotar todo el territorio y la adecuada comunicación entre sus puntos cardinales. Según Francisco Silvestre, el istmo tenía 87.300 habitantes en 1803 y casi 120.000 en 1843. En 1870 la población aumentó a cerca de 221.000 , después de recibir un importante contingente de trabajadores para construir el ferrocarril entre Ciudad de Panamá y Colón, con una densidad de 3 hab. $/ \mathrm{km}^{2}$. En 1896, 7 años antes de abandonar a Colombia, había 311.000 habitantes y 4 hab. $/ \mathrm{km}^{2}$. 
Cuadro 2

Población de Panamá

\begin{tabular}{lc}
\hline Año & Población \\
\hline 1778 & 80.044 \\
1803 & 97.312 \\
1843 & 129.657 \\
1851 & 148.108 \\
1870 & 221.119 \\
1896 & 316.054 \\
1911 & 391.745 \\
\hline
\end{tabular}

Fuente: Jaén $(1979,22)$.

Gráfica 1

Crecimiento demográfico de Panamá y Colombia

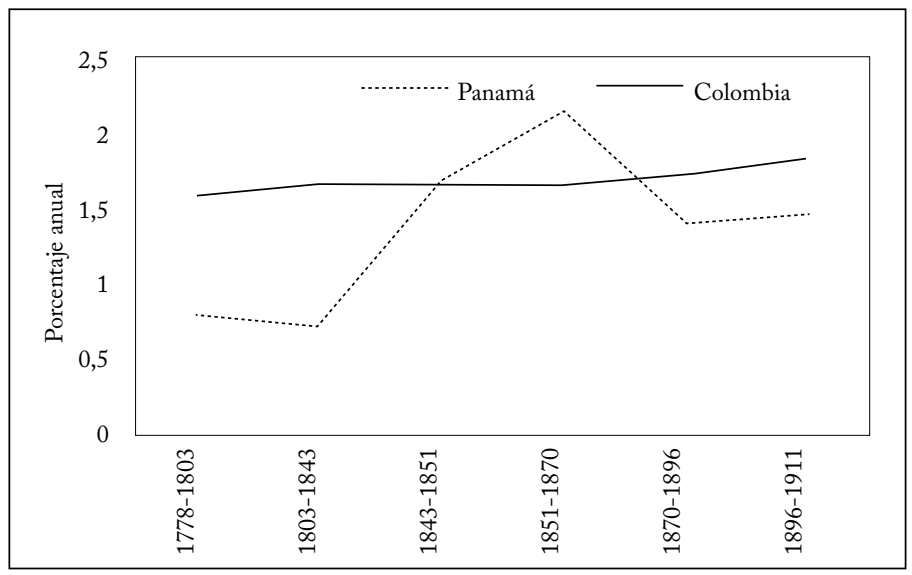

Fuente: Jaén (1979, 22); Flórez y Romero (2010, 389).

El ritmo de crecimiento demográfico fue bajo entre el censo de población de 1778 y el estimativo de Silvestre de 1803 (0,78\% anual), y se redujo aún más entre 1803 y 1843 (0,72\%). Pero subió al 1,6\% anual entre 1843 y 1851, similar al de la población de la República de la Nueva Granada, y superó el $2 \%$ anual entre esa fecha y 1870, cuando recibió importantes corrientes migratorias de San Andrés, Jamaica y Cartagena y se sintió el impacto de la llegada de médicos y vacunas que disminuyó la mortalidad endémica. Hasta 1843 el crecimiento fue muy bajo, menor que el de las provincias de la costa de la Nueva Granada, 1,2\% anual, y muy inferior al de las regiones de colonización antioqueña, superior al 1,8\% anual. Entre 1896 y 1911 volvió a ser inferior al 1,5\% anual. En este periodo se mantuvo un crecimiento similar, recurriendo moderadamente a la inmigración para construir el canal, pues los norteamericanos utilizaban mucha maquinaria pesada; en esta época se empiezan a controlar el paludismo y las fiebres con 
la desecación de pantanos y la aplicación de sulfas contra la malaria en las provincias de Panamá y Colón.

Las vicisitudes de la economía del istmo se reflejan en la población de la capital, que perdió la mitad entre 1822 (10.730) y 1843 (4.897), cuando se dislocaron las relaciones mercantiles de América Latina y el Caribe (Castillero, 2005). En 1870 Ciudad de Panamá registró 9.855 habitantes y unos 30.000 en 1885, en el apogeo de la construcción del canal francés, para volver a perder población en 1896, cuando descendió a 24.159 habitantes (Jaén, 1979, 32).

Cuadro 3

Inmigración extranjera a Panamá

\begin{tabular}{lc}
\hline Año & Inmigrantes \\
\hline 1849 & 800 \\
1850 & 13.484 \\
1851 & 21.180 \\
1852 & 13.201 \\
1853 & 23.690 \\
1854 & 25.917 \\
1855 & 28.704 \\
\hline
\end{tabular}

Fuente: Archivos franceses, citado en Vega, Jáuregui y Ortiz $(2003,50)$.

Cuadro 4

Crecimiento demográfico de las provincias

(Porcentaje entre los años señalados)

\begin{tabular}{lcc}
\hline & $1803-1843$ & $1843-1896$ \\
\hline Panamá & 10 & 240 \\
Colón & 10 & 90 \\
Coclé & 50 & 120 \\
Herrera & 40 & 50 \\
Los Santos & 40 & 80 \\
Veraguas & 60 & 60 \\
Chiriquí & 50 & 220 \\
Bocas del Toro & N.D. & 1400 \\
Darién & -20 & 750 \\
\hline
\end{tabular}

Fuente: Jaén $(1979,29)$.

E1 istmo volvió a ser cosmopolita desde 1850, cuando llegaron comerciantes, aventureros, ingenieros y trabajadores de China y del Caribe, dándole impulso a una economía hasta ese momento muy pobre, basada en un sistema de haciendas atrasado y desorganizado, y un comercio estancado.

Entre 1803 y 1843 el crecimiento demográfico de las provincias de Panamá y Colón solo fue del 10\% en esos 40 años; fue mayor en las demás provincias, excepto en Darién donde se redujo en un 20\%. Herrera, Los Santos, Veraguas y Chiriquí, con tierras relativamente salubres y aptas para la agricultura y la ganadería, tuvieron una po- 
blación creciente en la primera mitad del siglo XIX, lo cual refleja el proceso de colonización de Costa Rica que la convertiría en un próspero modelo de desarrollo cafetero y de integración con la economía mundial (Nugent y Robinson, 2010).

Para el período 1843 y 1896, "las provincias en las cuales tienen lugar las actividades relacionadas con la función de tránsito y aquellas que conocen la explotación a gran escala de materias primas o de productos agrícolas para la exportación habrán de demostrar los más altos índices de aumento de la población" (Jaén, 1979, 28). Los trabajos del ferrocarril y su puesta en marcha en 1855, y el inicio de las obras del canal francés en 1881, favorecieron la enorme expansión de Ciudad de Panamá y Colón. En Ciudad de Panamá la población se multiplicó por 3,4 y en Colón por 2 con la llegada de miles de extranjeros, sobre todo de Jamaica, e inmigrantes de las provincias del interior del país y de la provincia de Cartagena para atender las labores de construcción y del comercio que se abría vertiginosamente.

Más adelante, Bocas del Toro aumentó su población 15 veces entre 1843 y 1896, partiendo de una base muy pequeña, al convertirse en teatro de la expansión bananera impulsada por la United Fruit Company en América Central, que alcanzó el Caribe colombiano un poco más tarde; mientras que Darién se abrió a la explotación de tagua y otras maderas entre esos años. Las provincias rurales del interior tendrían un crecimiento demográfico más lento, con excepción de Chiriquí, colonizada por inmigrantes extranjeros aprovechando los suelos fértiles de las tierras altas, en especial la provincia de David que se convertiría en despensa de Panamá durante el siglo XX, incluido el cultivo del café. Y, en efecto, Chiriquí tendrá la expansión demográfica más alta del país durante el siglo XX.

Los conflictos civiles que envolvieron a Colombia durante los tres últimos lustros del siglo XIX y la Guerra de los Mil Días entre 1899 y 1902 produjeron un despoblamiento en las provincias de Coclé, Herrera y Santos, igual que en Darién. Uno de los teatros de operaciones de esa guerra fue precisamente el istmo, y la paz se selló en un barco de la armada norteamericana anclado en la ensenada de Panamá. La entrega de la zona del canal a Estados Unidos y su población panameña fue sustraída a los censos de población, unas 50.000 personas empadronadas hacia 1908 en Panamá y Colón que quedaron bajo jurisdicción norteamericana. 


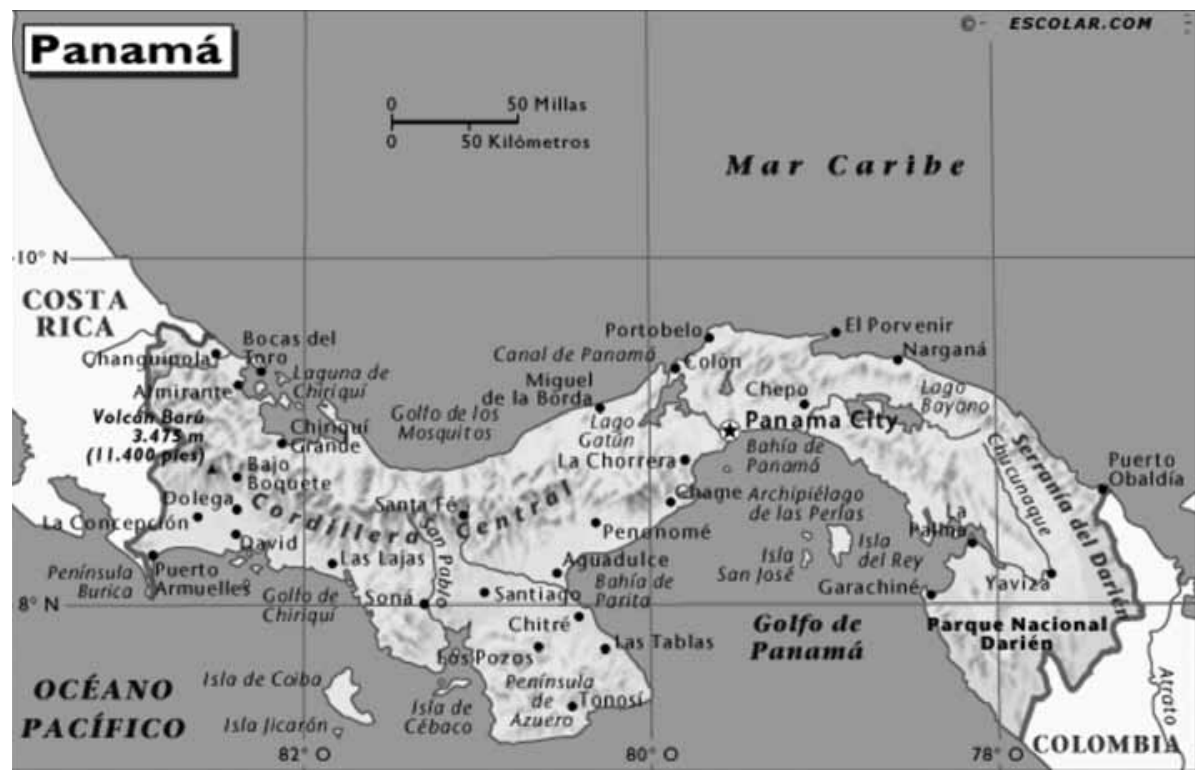

La geografía de Panamá es problemática para el desarrollo agropecuario por las condiciones extremas de humedad y las selvas tupidas en buena parte de su territorio. $\mathrm{El}$ istmo

es un planicie verde de topografía rizada, enmarcadas al este y oeste por montañas cubiertas también de una selva virgen, drenada por ríos sinuosos con aguas espesas, chocolates, que terminan en grandes pantanos litorales que tiñen las costas del Pacífico y del Caribe de esos colores amarillos, sepias rosados y verdes lodosos [...] La naturaleza excesiva, aplastante, a un precio elevadísimo puede ser temporalmente dominada, contenida, pero nunca vencida. La selva tropical protege un suelo frágil y un subsuelo cuya roca madre, lo más menudo friable, profundamente alterado a lo largo de varios metros de espesor, se presta para los deslizamiento y los derrumbes con gran facilidad [...] Todo esfuerzo parece vano, todo es un eterno recomenzar; la selva está presta a tragarse, rápidamente, el espacio ganado provisionalmente por el hombre [...] la geografía grandiosa, generosa en exceso, lo es también en dificultades (Jaén et al., 1999, 20 y 24).

Pero la naturaleza se torna más amable a medida que se avanza hacia occidente, con tierras fértiles, protegidas por la cordillera central, las cuales reciben abundantes lluvias temporales que hacen posible el desarrollo agropecuario en la provincia de Chiriquí, alrededor de la ciudad de David y en Bocas del Toro, frente al Mar Caribe.

Justo Arosemena, en su opúsculo El Estado Federal, advertía que el paso por el istmo no tendría un efecto multiplicador importante sobre una economía atrasada y limitada por su geografía:

La rapidez con que se hará el tránsito de viajeros y mercancías, el monopolio que naturalmente ejercerá la empresa en almacenes y aún en hoteles a 
las extremidades del camino, la facilidad que tendrán los cargamentos para llegar a su mercado sin quedar depositados en el istmo, la falta de industria doméstica que exporte por el ferrocarril y reciba por el mismo en cambio artefactos extranjeros; estas y otras circunstancias mantendrán aquel territorio en cierto estado económico, que aunque no llegue a la miseria ni al abatimiento de 1848, tampoco será muy lisonjero para el que quiera ver desenvuelta la riqueza, como pudiera serlo en el istmo con sus feraces tierras, y un millón de habitantes que bien puede contener (Arosemena, 1982, 77).

Panamá, igual que el resto de la Nueva Granada, heredó instituciones hispánicas que daban la tierra a la élite y le permitían controlar la mano de obra mediante el esclavismo o contratos informales y serviles de arrendamiento, que se manifestaron con mayor fuerza en el istmo: centro comercial esclavista por excelencia que tendrá una población afrodescendiente a la que se tratará con dureza hasta la emancipación total de 1851. Por ejemplo, en 1843 se aprobó una ley que reprimía "los movimientos sediciosos de esclavos". Había también trabajo forzado en el "servicio personal subsidiario", mediante el cual un hacendado contribuía en especie al fisco o al culto aportando el trabajo de sus peones para "reparación de la muralla, reparo de cementerios e iglesias". En los años veinte y treinta se repartieron resguardos indígenas y quedaron expuestos a los elementos y al mercado. En 1853 se aprobó una ley que abolió la pena de muerte y derogó las ordenanzas contra la vagancia que, por lo general, castigaban con trabajo forzado a los infractores (Kam, s.f.b).

Todo esto nos revela una sociedad donde aún no predominaba el trabajo libre, los terratenientes controlaban el tiempo de sus arrendatarios, la productividad de ese trabajo era muy baja y no se podía asignar a las demandas del mercado que surgiría con fuerza en los años cincuenta con la construcción del ferrocarril. Debido a estas condiciones la sociedad panameña y la colombiana también eran muy pobres; las grandes obras públicas debían ser emprendidas por capital extranjero y ejecutadas por trabajadores asalariados de otras regiones, aunque esos choques produjeron fisuras sociales y propiciaron la liberación de la mano de obra de sus ataduras feudales.

\section{LA CONSTRUCCIÓN DEL FERROCARRIL}

Panamá debió tener un alto crecimiento económico a partir de la construcción del ferrocarril que conectó Ciudad de Panamá en el Pacífico con Colón en el Atlántico. Una vez iniciado el servicio en 1855, el istmo fue el paso más corto -en tiempo- entre el Este y el Oeste de Estados Unidos, con un intenso tráfico por la fiebre que desató el oro de California y atrajo a miles de individuos de todas las 
nacionalidades en busca de fortuna. Según Maurer y Yu, entre 1849 y 1869 más de 600.000 pasajeros hicieron tránsito entre Nueva York y San Francisco por el istmo (gráfica 2). La culminación del ferrocarril transcontinental en Estados Unidos en 1869 alivió la presión al camino por el istmo, aunque siguió siendo importante para el tráfico entre Asia, Chile, Perú, Ecuador, el Pacífico colombiano y el Atlántico.

Gráfica 2

Pasajeros transportados por Panamá

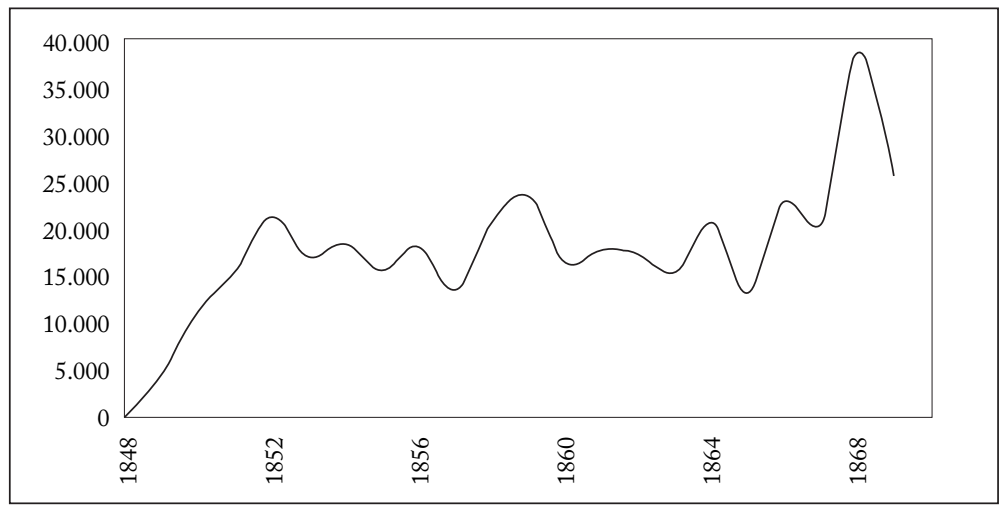

Fuente: Maurer y Yu (2010, 38).

El plan de construir un ferrocarril entre Ciudad de Panamá y Colón fue iniciativa de un grupo de empresarios franceses, quienes en 1845 organizaron la Compagnie de Panamá que obtuvo una concesión del gobierno colombiano por 99 años. Pero la revuelta de la Comuna de París en 1848 impidió que la empresa cancelara su depósito con el gobierno colombiano y el acuerdo se echó para atrás. Un empresario estadounidense, William Henry Aspinwall, creó la Panamá Railroad Company en 1849 y emitió un millón de dólares en acciones, pero solo pudo colocar la mitad en Wall Street. Entonces abrió negociaciones con el gobierno colombiano que le otorgó un $5 \%$ de los ingresos brutos y el 3\% de los dividendos; al cabo de 20 años el gobierno tendría la opción de comprar los rieles por 5 millones de dólares. E1 acuerdo fue aprobado por el gobierno y ratificado por el Senado en 1850. Al parecer el estado soberano no recibió nada en este primer acuerdo económico, o por lo menos no está registrado en los presupuestos. Es claro que comenzó a recibir $\$ 25.000$ anuales, un $10 \%$ de lo que recibía Bogotá, cuando se hizo un nuevo contrato con la Panamá Railroad en 1867, y el monto figura en la mayor parte de los presupuestos que encontramos en la Biblioteca Nacional. Pero con el nuevo contrato 
Colombia recibió un millón de dólares por una vez y una anualidad de US $\$ 250.000$, de la cual solo reconoció a Panamá el 10\% mencionado.

Antes de eso, Aspinwall había iniciado una ruta para el transporte de correo y de pasajeros desde Nueva York, Nueva Orleans y Oregón a Ciudad de Panamá, y por un camino de mulas a partir de Colón, que comenzó a ser cada vez más utilizada por los aventureros contagiados de la fiebre del oro, en vez de utilizar la mucho más larga por el Cabo de Hornos. En 1849, casi 6.500 personas arribaron a California vía Panamá, contra 11.770 por el sur del continente. En 1853, la vía panameña, que podía utilizar parcialmente el ferrocarril, había transportado a 15.500 personas y era la más utilizada para colonizar el nuevo territorio en la década de los cincuenta.

Con el descubrimiento de oro en California, se aceleró la actividad económica; hombres de diversa contextura somática emprendieron una veloz carrera cuya meta era hacer fortuna. Así, "el paso de caudales, mercaderías, equipajes y pasajeros por los puertos de Panamá y Chagres, dio ocupación a gran número de personas e inició el prodigioso movimiento económico" (Kam, s.f.a, 35).

Cuadro 5

Ferrocarril de Panamá, ingresos, gastos y pagos a la Nación

\begin{tabular}{lrrrc}
\hline Año & Ingresos & \multicolumn{1}{c}{ Gastos } & Utilidad & Pagos a la Nación \\
\hline 1852 & 250.162 & 73.999 & 176.163 & 4.403 \\
1853 & 322.428 & 113.950 & 208.478 & 6.143 \\
1854 & 453.572 & 116.542 & 337.030 & 5.562 \\
1855 & 1.099 .069 & 284.156 & 814.913 & 14.895 \\
1856 & 1.360 .731 & 530.249 & 830.492 & 27.040 \\
1857 & 1.305 .819 & 649.302 & 656.518 & 27.310 \\
1858 & 1.506 .076 & 858.589 & 847.388 & 27.802 \\
1859 & 1.925 .444 & 795.748 & 1.129 .696 & 27.892 \\
1860 & 1.550 .876 & 702.889 & 847.987 & 27.914 \\
1861 & 1.539 .860 & 611.663 & 928.197 & 27.923 \\
1862 & 1.712 .281 & 729.850 & 983.331 & 27.966 \\
1863 & 2.027 .438 & 829.747 & 1.197 .691 & 29.498 \\
1864 & 2.489 .222 & 1.029 .769 & 1.459 .453 & 34.000 \\
1865 & 2.175 .885 & 1.002 .051 & 1.173 .834 & 38.800 \\
1866 & 2.424 .978 & 1.208 .365 & 1.216 .613 & 45.700 \\
1867 & 2.717 .393 & 1.183 .785 & 1.533 .607 & $1.131 .500^{*}$ \\
1868 & 3.810 .192 & 1.873 .114 & 1.937 .079 & 250.000 \\
1869 & 2.299 .252 & 1.501 .446 & 797.811 & 250.000 \\
1870 & 1.383 .450 & 1.063 .218 & 320.232 & 250.000 \\
1871 & 1.883 .885 & 1.084 .000 & 800.000 & 250.000 \\
\hline
\end{tabular}

* Incluye el pago de una anualidad por un millón de dólares.

Fuente: Correa (2011).

La construcción del ferrocarril se inició a finales de 1850 desde un sitio que los norteamericanos habían bautizado como Navy Bay y que 
dio lugar a un nuevo pueblo, Aspinwall, el cual llegó a ser la ciudad de Colón. Los contratistas enfrentaron gran escasez de trabajadores locales, que rechazaban trabajar arduamente por salarios inferiores a los que ganaban conduciendo pasajeros de un océano al otro por el camino de mulas o que estaban atados servilmente en las haciendas de la región. La empresa intentó contratar trabajadores norteamericanos, pero con salarios inferiores a los que se pagaban en California no logró reunir los contingentes requeridos. Recurrió entonces a trabajadores chinos a los que les of recía arroz, te y opio, de los cuales llegaron 700, que en su mayoría no resistieron las condiciones del bosque tropical húmedo y murieron de malaria o se suicidaron, de modo que " $80 \%$ de la fuerza de trabajo china pereció o abandonó y mendigos destituidos chinos se volvieron un espectáculo frecuente en Ciudad de Panamá” (Maurer y Yu, 2010, 43). La empresa empleó entonces trabajadores jamaiquinos, norteamericanos y cartageneros en cantidades que alteraron en forma permanente la demografía de una provincia que entonces tenía unos 138.000 habitantes.

Originalmente se pensó que el ferrocarril se podría construir en dos años con un costo de US $\$ 1.350 .000$, pero se terminó en cinco años, después de muchas vicisitudes y tremendas pérdidas en vidas humanas por la fiebre amarilla y el paludismo, con costos muy superiores, unos US\$8 millones hacia 1858 (McCullough, 1977, 35). Sin embargo, los ingresos crecieron desde el mismo momento en que se terminó el primer tramo de 7 kilómetros, pues se utilizaba en combinación con el camino de mulas para transportar a los viajeros, de modo que en 1854 los ingresos brutos del ferrocarril superaron el millón de dólares. Las ganancias de los 6 primeros años fueron de US\$7 millones, con un dividendo del 15\% sobre el valor de la acción que en algunos momentos llegó al 44\%, siendo una de las acciones más valorizadas en el mercado accionario de Nueva York (ibíd., 35). Esa era la prueba más palpable de la altísima rentabilidad que tendría una comunicación más expedita entre los dos océanos para la economía norteamericana y para la economía global. La gesta del ferrocarril de Panamá fue enorme y exitosa, a pesar de que en 1869 el Este y el Oeste de Estados Unidos quedaron comunicados por el ferrocarril transatlántico y el tráfico por Panamá disminuyó sensiblemente.

Según Castillero, en un principio el impacto multiplicador de la ruta del istmo fue enorme:

La excitación de California abrió un nuevo e inesperado mercado a los agricultores y ganaderos, sobre todo para el consumo de granos y carne de res, tanto para suplir la demanda de miles de pasajeros en tránsito, como de las diversas navieras que aportaban en Panamá y Colón, todo lo cual estimuló 
la producción agropecuaria a escalas antes desconocidas. Éste fue el caso de Chiriquí. Para 1853 ya Chiriquí producía suficiente arroz y maíz para abastecer el consumo de la provincia y enviar el excedente a la capital (Castillero, 2005).

Pero el efecto sobre la actividad doméstica de la regularización provocada por el ferrocarril no fue del todo favorable:

Contra lo que podría esperarse, la apertura del ferrocarril en 1855 tuvo un efecto paralizante en el comercio de Panamá, ya que la Compañía había obtenido, entre otros importantes privilegios, el control de la isla Manzanillo, donde se erigió la ciudad de Colón, que la Compañía utilizaba como gran estación y campamento, de tal suerte que cuando los pasajeros llegaban a Panamá de California, no permanecían en esta ciudad sino que de inmediato se subían al ferrocarril para viajar a Colón y de allí trasladarse en vapor a su destino final. De esa manera, los grandes gastos que anteriormente hacían los pasajeros en Panamá cesaron y muchas casas comerciales, hoteles y restaurantes se vieron obligadas a cerrar entre 1855 y 1856 (ibíd., 49).

A la empresa también se le concedió un extenso territorio, excluido de la explotación económica, lo que llevó a "la desventura de no poder incorporar a la producción agrícola 300.000 acres (120.000 ha), otorgados mediante contrato, y terrenos aledaños a esta arteria vial, que debido a la actitud de la compañía de no invertir en el istmo, no permitió la explotación de las mismas a lo largo de todo el siglo XIX" (Kam, s.f.a, 41).

Como muestra el cuadro 5, en 1862 el ferrocarril tuvo unos ingresos de 1.700.000 dólares y unos gastos de 730.000, para un ingreso neto de casi un millón de dólares. Suponiendo que los gastos salariales fueron de 200.000 dólares, el valor agregado del ferrocarril fue de 1.200.000 dólares anuales, un PIB por habitante de casi 6 dólares, aunque la parte del ingreso que se gastaba en Panamá excluía las utilidades repatriadas. Así mismo, una parte del consumo de la fuerza de trabajo y los bienes intermedios consumidos por el ferrocarril eran importados, de modo que el impacto real sobre el PIB del estado soberano ha debido ser menor.

¿Qué tan importante pudo ser el valor agregado por el ferrocarril a un PIB hipotético de Panamá? Un cálculo a mano alzada, derivado del recaudo tributario, suponiendo que rondaba el 3\% del PIB, nos daría que en 1870 sería del orden de $\$ 10$ millones y de $\$ 45$ por habitante, superior al promedio de los Estados Unidos de Colombia que en esa época debía ser de $\$ 33$ por habitante. En todo caso, el valor agregado del ferrocarril sería de un 13\% del PIB de Panamá, lo que indica su gran importancia económica, sin contar sus efectos sobre el comercio internacional y de cabotaje del istmo.

¿Cómo se repartían los ingresos entre el gobierno central y el estado soberano de Panamá? Según el registro de las operaciones entre 
1864 y 1878, al gobierno central le entró una suma considerable e importante para sus finanzas, casi $\$ 4,4$ millones, cerca de un $8 \%$ de sus ingresos totales (cuadro 6). Pero no solo eso:

las anualidades pactadas jugarían un papel central en el establecimiento y financiación del Banco Nacional durante la administración Núñez, pues para el establecimiento de buena parte del capital necesario para su puesta en marcha se contrató un préstamo por dos y medio millones otorgado al gobierno por la empresa Morton, Blis \& Co. de Nueva York (Correa, 2011b).

Cuadro 6

Ingresos por el ferrocarril para el Gobierno Central

\begin{tabular}{lrrr}
\hline Año & Ferrocarril & \multicolumn{1}{c}{ Total } & Porcentaje \\
\hline 1864 & 34.000 & 2.125 .000 & 1,6 \\
1865 & 34.000 & 2.125 .000 & 1,6 \\
1866 & 1.131 .500 & 3.333 .334 & 33,9 \\
1867 & 497.904 & 3.054 .625 & 16,3 \\
1868 & 250.000 & 3.289 .474 & 7,6 \\
1869 & 250.000 & 2.873 .563 & 8,7 \\
1870 & 250.000 & 3.100 .000 & 8,1 \\
1871 & 253.150 & 3.223 .136 & 7,9 \\
1872 & 250.000 & 4.000 .000 & 6,2 \\
1873 & 250.000 & 3.907 .158 & 6,4 \\
1874 & 250.000 & 3.804 .839 & 6,6 \\
1875 & 225.000 & 3.749 .586 & 6,0 \\
1876 & 250.000 & 3.852 .970 & 6,5 \\
1877 & 250.000 & 6.574 .115 & 3,8 \\
1878 & 250.000 & 5.893 .075 & 4,2 \\
Total & 4.425 .554 & 54.905 .875 & 7,8 \\
\hline
\end{tabular}

Fuente: Cuadro 5 y Kalmanovitz y López (2010).

Para los Estados Unidos de Colombia el recaudo fiscal era en promedio de unos $\$ 3.800 .000$ anuales, así que los ingresos por el ferrocarril, $\$ 250.000$, representaban cerca del $6,6 \%$, pero para los panameños era en promedio de $\$ 25.000$ anuales, el 8,3\% de sus ingresos fiscales, $\$ 300.000$ por año. Si se pregunta qué tan equitativo era que la renta que pagaba la empresa del ferrocarril a los Estados Unidos de Colombia se repartiera en un $90 \%$ para el gobierno central y en un $10 \%$ para Panamá, la respuesta es que no era muy justo.

Una vez se normalizó el tránsito por el ferrocarril en 1855,

los Estados Unidos mantuvieron un protectorado militar en el istmo. La soberanía de Colombia estuvo subordinada y limitada, según lo manifestó el dirigente liberal Benjamín Herrera, a la permanente presencia militar norteamericana. En las bahías de Panamá y Colón siempre estaban fondeados buques de guerra de la armada de los Estados Unidos (Alarcón, 2010, 109).

Como ya se dijo, el acuerdo con el gobierno colombiano terminaba en 1870, y ya en 1867 se firmó uno nuevo que contemplaba un pago anual de US $\$ 250.000$ y un contado de US\$1 millón, además de la participación del 3\% de los dividendos que abonaba a sus accionistas. 
¿Qué parte del pago al gobierno central se compartió con el gobierno del estado soberano? Del millón de dólares al parecer no recibió nada, solo la anualidad de $\$ 25.000$ que le entraba a Ciudad de Panamá.

En el futuro, cuando se terminara el canal, mejoraría la participación del istmo en la renta. En el contrato firmado entre el país y la Sociedad Civil Internacional del Canal Interoceánico en 1878, para construir la vía por los franceses, la participación del estado soberano de Panamá sería de una quinta parte del total: 5\% del producto bruto en los primeros 25 años, $6 \%$ en los siguientes 25 años y 7 y $8 \%$ en los 25 años posteriores, sin que fuera inferior a $\$ 250.000$ anuales (Cavelier, 2003, 47). Esto mejoraba sustancialmente la porción de Panamá frente al pasado, pero desafortunadamente toda la empresa fracasó y los beneficios nunca se materializaron.

Cuadro 7

Exportaciones de Panamá

\begin{tabular}{lc}
\hline Periodo & Pesos \\
\hline $1847-1857$ & 200.000 \\
$1864-1866$ & 580.000 \\
1870 & 800.000 \\
\hline
\end{tabular}

Fuente: Castillero (2005).

El aumento del comercio de cabotaje elevó las exportaciones de $\mathrm{Pa}-$ namá: perlas, madera de tagua, carne y diversos productos agrícolas. Castillero (2005) reconstruye las exportaciones en forma aproximada: entre 1847 y 1870 se multiplicaron por cuatro. Suponiendo un PIB de \$9 millones para el Estado Federal de Panamá ${ }^{2}$ las exportaciones representaban entre un 6 y un $8 \%$ en la década de los sesenta, aunque la exportación de servicios aumentaría la participación en otros 2 puntos. Se trataba entonces de una economía cerrada y trabada en su potencial agropecuario, aunque cada vez menos. Comparada con los Estados Unidos de Colombia, que tuvo brotes exportadores a veces cuantiosos que acercaban el coeficiente de exportación al 20\% del PIB entre 1863 y 1886, Panamá era más cerrada, a pesar de su posición geográfica abierta al mundo.

Con la apertura del ferrocarril que unía Nueva York y Chicago con California y Oregón, en 1869, el empleo y la actividad económica en Panamá se redujeron sustancialmente y el estado soberano entró en una fase recesiva que solo empezó a revertirse con la inversión francesa que inició en 1881 los trabajos para construir el canal. "El

\footnotetext{
${ }^{2}$ Se extrapola suponiendo que el ingreso fiscal del estado soberano equivale a un 3\% de su PIB. En 1870, los ingresos fiscales eran de $\$ 300.000$ que divididos por 0,03 dan el resultado mencionado.
} 
comercio entre Nueva York y San Francisco alcanzó en 1868 más de $£ 14$ millones. Puesta en funcionamiento la primera línea férrea transcontinental de Estados Unidos entre esas dos ciudades, en mayo de 1869, al año siguiente el tráfico por Panamá descendió a $£ 720.000 ”$ (Alarcón, 2010, 105), o sea que se redujo en un 95\%. Aunque el ferrocarril perdió valor con la reducción de su actividad, la Compagnie Universelle du Canal Interoceanique consideró que el canal debía construirse por la misma ruta por la que transitaba el ferrocarril y lo adquirió en 1881. La demanda de los franceses devolvió brillo a la acción del ferrocarril de Panamá, cuyo valor aumentó en 4 veces entre 1870 y 1881, lo que no le sirvió mucho a los panameños.

\section{CONDICIONES POLÍTICAS EN EL ISTMO}

Panamá soportó una constante inestabilidad política, reflejo de los desórdenes nacionales y de las confrontaciones locales entre liberales y conservadores o entre facciones de estos partidos. Antes de la Constitución de 1863, que introdujo la figura presidencial por un periodo de cuatro años, las administraciones territoriales contaban con un gobernador elegido cada dos años. Pero el propio estado soberano decidió modificar su constitución y debilitar el poder del ejecutivo, con un periodo presidencial de dos años. Los cambios en el poder ejecutivo reflejan la inestabilidad política reinante: entre 1855 y 1862 hubo nueve gobernadores y solo debió haber cuatro; entre 1862 y 1886 debía haber doce presidentes, pero desfilaron treinta.

Una explicación plausible de la inestabilidad política en el istmo es que no se organizó una hegemonía alrededor de un grupo de interés o de una coalición de varios grupos, en particular porque era tan grande la disparidad numérica de la élite blanca descendiente de españoles y la de comerciantes extranjeros frente a una población de mestizos, mulatos y negros que vivía en los intramuros de Ciudad de Panamá o que ocupaba desordenadamente Colón, así como el resto del territorio, que no se contaba con una fuerza política importante que prestara estabilidad a cualquier fracción de las élites. Aunque la fuerza económica de los comerciantes con negocios internacionales era mayor que la de los hacendados $\mathrm{u}$ otras facciones regionales, no fue estable ni creciente a lo largo del siglo XIX. Por el contrario, los ciclos económicos eran muy volátiles, los auges de relativa corta duración y los colapsos de la actividad de gran magnitud. Por último, el propio proceso de centralización política en el estado soberano era muy incipiente y eventualmente culminó con la macrocefalia de las dos ciudades situadas en los extremos del tránsito interoceánico. Estos 
factores pesarían en casi todos los estados soberanos de los Estados Unidos de Colombia, menos en Antioquia donde hubo una larga hegemonía de los mineros que se tornaron comerciantes y eventualmente industriales. Este sector lideró el proceso de modernización conservadora que viviría Colombia durante el siglo XX.

Desde 1856 hubo un cambio fundamental en la política colombiana al permitir la participación electoral de toda la población masculina mayor de 21 años, sin ningún requisito de propiedad o alfabetismo. Pero algunos estados no la adoptaron, como Cundinamarca, y otros prescindieron de ella porque las élites no se exponían a jugar con política de masas. Panamá experimentó grandes conmociones con la democratización de su política: "Durante la vigencia de la Constitución de Rionegro Panamá vivió una experiencia inédita. Por primera vez en su historia, de forma consistente y reiterada, grupos sociales que hasta entonces habían estado marginados del poder político y excluidos de toda consideración social tuvieron acceso real al poder político" (Aparicio, 2004a, 233).

Entre 1862 y 1879 los comerciantes urbanos ocuparon la presidencia siete años, los grupos rurales dominantes tres años y lo que Aparicio llama arrabal santanero (el barrio de negros y mulatos de Ciudad de Panamá) ocho años. Buenaventura Correoso y Rafael Aizpuro fueron los caudillos liberales más destacados que ascendieron a la presidencia del Estado (ibíd., 227). Los sectores afrodescendientes organizaron el Partido Liberal Negro.

La inestabilidad en los estados soberanos se debía a que podían convocar asambleas constitucionales que cambiaban las reglas acordadas por los constituyentes en 1863, lo que aumentaba la rotación, aun sin contar los casos de presidentes que no podían terminar su corto mandato y entregaban el poder al primer o segundo delegado o de aquellos en que la guardia del estado soberano daba un golpe al presidente y lo sustituían por un militar. La división del mando militar entre una débil guardia nacional y las guardias de los estados soberanos aumentaba aún más la inestabilidad política, pues no podía actuar para solucionar conflictos dentro de una misma región. Para rematar, las frecuentes asonadas ponían en riesgo el tránsito del ferrocarril entre Colón y Ciudad de Panamá, lo cual atrajo la intervención de la marina estadounidense en repetidas ocasiones, produciendo dislocaciones políticas adicionales, incluido el cambio de mandatarios más afines con los intereses del ferrocarril, para proteger el tránsito de personas y mercancías estadounidenses. 
Es obvio que los cambios frecuentes en el ejecutivo malograban cualquier asomo de programa de gobierno y que se hicieran reformas que contrarrestaran los agudos vaivenes económicos que surgieron con la construcción del ferrocarril y su puesta en marcha, seguidos 15 años más tarde por la caída del tráfico de pasajeros en 1869. Debieron pasar otros 12 años de estancamiento para que se iniciara la obra faraónica del canal en 1881, que reactivó los circuitos productivos del istmo, hasta que también colapsó siete años después por el equivocado trazo de la obra que se planeó sin las esclusas que exigía la diferencia de nivel entre los dos océanos. Hubo además enormes escollos creados por el difícil acceso a mano de obra, el clima, los mosquitos y las enfermedades que portaban.

La inestabilidad política se presentó en casi todos los estados soberanos, a excepción de Boyacá y Antioquia que eran relativamente homogéneos ideológicamente, ambos conservadores, aunque tampoco escaparon a los conflictos de orden nacional o a que estados vecinos de signo político contrario los invadieran e intentaran imponer sus preferencias. Panamá presentaba un problema más complejo que los demás estados soberanos pues tenía una burguesía comercial articulada, de orientación liberal, que se enfrentaba a menudo con los bastiones conservadores del interior, surgidos de economías ganaderas y en menor medida agrícolas, en medio de un pueblo empobrecido con poco acceso a la educación atendida solo parcialmente por las élites.

Como se verá, la inclusión política del "arrabal" determinó que en los presupuestos del estado soberano se asignaran recursos para la educación, que luego aumentaron, en especial en la década de los setenta. Pero las instituciones que permitían expresar los intereses de las clases subordinadas tocarían fin con la Constitución de 1886 que restringió la ciudadanía a quienes tenían una profesión u oficio legítimos como medio de subsistencia, eran alfabetos y tenían ingresos anuales de más de $\$ 500$ (unas diez veces el ingreso promedio por habitante) o propiedades con valor superior a $\$ 1.500$. Además, las elecciones para Presidente de la República y senadores eran indirectas, con delegados a menudo designados por el poder ejecutivo, y elecciones directas para concejales municipales, diputados a las asambleas departamentales y representantes a la Cámara. Los movimientos políticos que respaldaban a los dirigentes liberales fueron reprimidos ferozmente, sus publicaciones clausuradas y sus líderes encarcelados, desterrados y a veces fusilados. En Panamá la represión del partido liberal comenzó en 1885, cuando el caudillo Pedro Prestán encabezó una rebelión aplastada por la guardia conservadora, con apoyo de 
tropas norteamericanas. Desde entonces, "el arrabal perdió su prominente posición política y sus principales cabecillas fueron perseguidos, arrestados o exiliados" (Aparicio, 2004b, 237).

\section{LAS CUENTAS FISCALES DE PANAMÁ}

El gran desorden político que caracterizó al estado soberano de Panamá y la falta de personal que supiera de contabilidad y finanzas dejaron grandes vacíos en la información fiscal, además de los frecuentes cambios de metodología. No habiendo podido conseguir datos sobre el comportamiento de caja del estado soberano, nos atenemos a los ingresos y gastos presupuestados, que aunque son una proyección a veces optimista no deben estar demasiado lejos de la realidad fiscal.

La serie más larga que recopilamos (gráfica 3) muestra unos ingresos muy magros como provincia alejada de la República de Nueva Granada en 1848 y de $\$ 95.000$ en 1851 . Con los ingresos por el uso del ferrocarril llegaron a $\$ 150.000$ en 1856 , que se duplicaron con el nuevo acuerdo sobre su manejo que se firmó en 1866 y que se mantuvo hasta 1874 , a pesar de que el ferrocarril continental estadounidense acaparó el grueso del comercio y el transporte de pasajeros a partir de 1869 y la operación panameña perdió rentabilidad. Los ingresos se redujeron a unos $\$ 220.000$ en 1876 y $\$ 250.000$ en 1882 , señalando un nuevo periodo de estancamiento. Entre 1848 y 1872, el ingreso promedio de Panamá fue de $\$ 220.000$ anuales. Los datos agregados que recopilamos se presentan en el cuadro 8.

Gráfica 3

Panamá

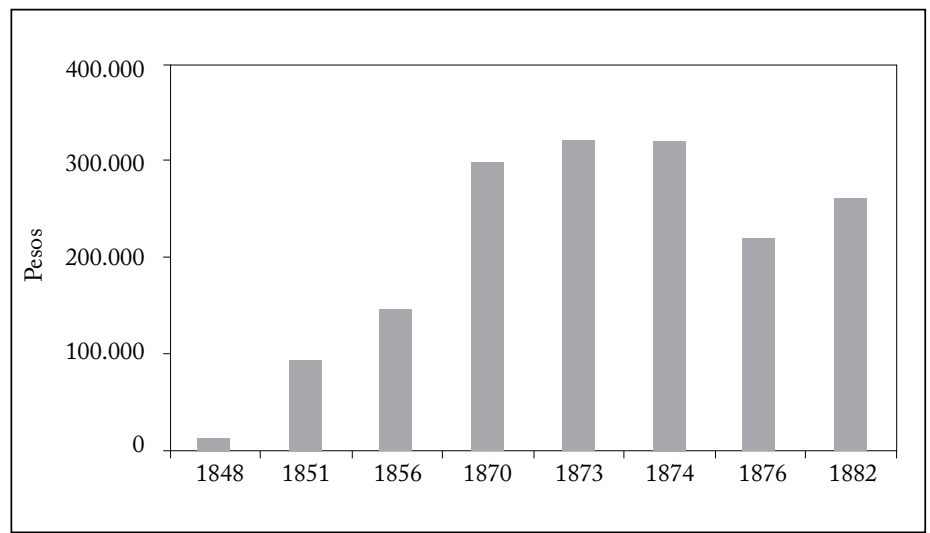

Fuente: Kalmanovitz y López (2010). 
Cuadro 8

\begin{tabular}{llrrr}
\hline Año & Ingresos & Gastos & Déficit & Deuda \\
\hline 1856 & 127.500 & 185.086 & -57.586 & 42.288 \\
1857 & 188.613 & 271.816 & -83.203 & 68.091 \\
1858 & 168.845 & 150.000 & 18.845 & 5.320 \\
1859 & 169.414 & 199.615 & -30.201 & 21.200 \\
1860 & 150.100 & 236.934 & -86.834 & 71.200 \\
1861 & 174.322 & 178.537 & -4.215 & 5.700 \\
& & & & \\
1865 & 249.926 & 253.897 & -3.971 & 1.000 \\
1866 & 355.516 & 389.949 & -34.433 & 43.800 \\
& & & 0 & \\
1871 & 269.261 & 321.841 & -52.580 & 42.967 \\
& & & & \\
1873 & 261.856 & 271.784 & -9.928 & 24.946 \\
1874 & 321.513 & 321.523 & -10 & 29.930 \\
1875 & 259.402 & 290.111 & -30.709 & 29.219 \\
1876 & 250.800 & 257.619 & -6.819 & 45.813 \\
1877 & 298.455 & 325.878 & -27.423 & 53.500 \\
1878 & 279.890 & 388.147 & -108.257 & 89.603 \\
1879 & 259.979 & 258.823 & 1.156 & 40.000 \\
1880 & 300.628 & 303.207 & -2.579 & 39.000 \\
& & & & \\
1883 & 329.949 & 447.403 & -117454 & 33.577 \\
1884 & 338.839 & 543.336 & -204497 & 34.197 \\
\hline
\end{tabular}

Fuente: Presupuestos de Panamá, Leyes de Panamá.

Entre 1855 y 1860 los ingresos proyectados promediaron $\$ 163.000$ anuales $y$, en general, los gastos presupuestados eran considerablemente mayores, lo que no tiene mucho sentido. Los montos asignados para atender las deudas contraídas con ciudadanos prestantes, generalmente comerciantes, a menudo de carácter forzoso, se mueven en la misma dirección de los déficits pero no son proporcionales. Quizá la caja debía ajustarse cuando los ingresos, aun los presupuestados, no alcanzaban a enjugar los egresos.

Solo contamos con información de dos años de la década de los sesenta, en los cuales los ingresos aumentaron sustancialmente, a más de $\$ 260.000$. Uno de los años está en relativo equilibrio, pero el siguiente se proyecta un déficit considerable. La deuda en 1865 es de solo $\$ 1.000$. La deuda registrada para 1866 es de $\$ 43.800$.

En la década de los setenta son pocos los años en los que los ingresos se presupuestan en más de $\$ 300.000$, y el promedio se acerca a $\$ 275.000$ anuales, aunque es una fase en la que el transporte de carga y de pasajeros es muy inferior al de los prósperos años sesenta. Solo hay una año con superávit y en 1878, por ejemplo, hay un déficit de más de $\$ 108.000$, equivalente a un $40 \%$ de los ingresos proyectados. 
Gráfica 4

Ingresos y gastos presupuestales

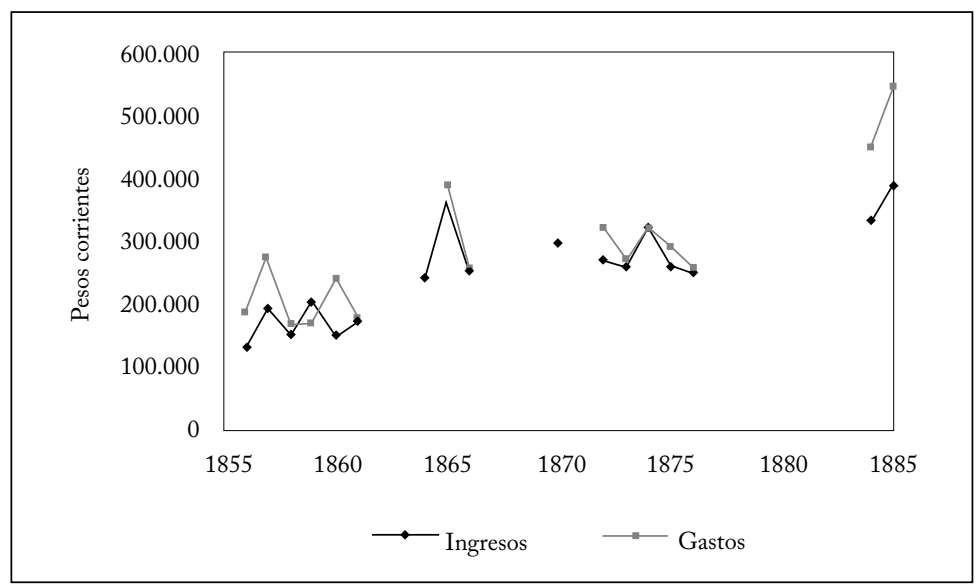

En la gráfica 5 se aprecia una relativa correlación entre déficit y deuda pero, como ya se dijo, no son estrictamente proporcionales. El déficit de 1884 fue gigantesco y pudo estar asociado a la guerra de 1885 que también se libró en Panamá, por primera vez en la historia de las guerras civiles del país. En el Anexo 1 mostramos un ejemplo de los decretos que imponían préstamos a los municipios de una provincia y a los individuos que podían pagarlos, de modo que no es seguro que se pagaran del todo, puntualmente o a las tasas de interés estipuladas.

\section{Gráfica 5}

\section{Déficit fiscal y deuda}

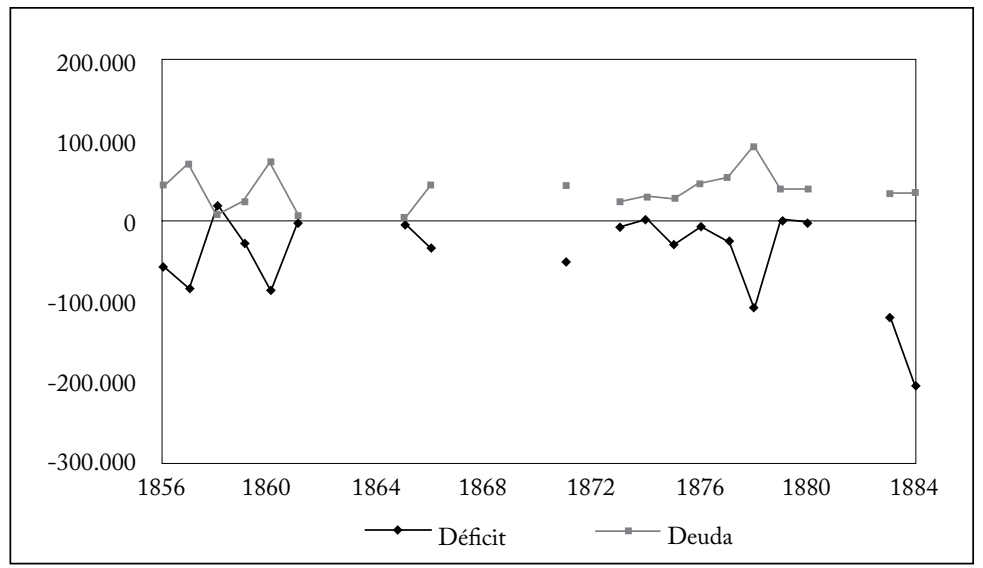


Cabe destacar que los mandatarios panameños intentaron y al fin lograron gravar a las casas comerciales establecidas en Colón y Ciudad de Panamá. En 1853 fijaron una tasa del 10\% a sus utilidades netas y de $\$ 2$ por pasajero transportado, además de un derecho de tonelaje por el uso de los dos puertos, pero la medida fue rechazada con amenazas por los comerciantes extranjeros y por el gobierno de Estados Unidos, que esgrimió el tratado Mallarino-Bidlack de 1846, el cual eximía de impuestos a las mercancías en tránsito y establecía que los ciudadanos estadounidenses y neogranadinos tendrían iguales derechos. Las autoridades políticas se vieron forzadas a no aplicar el decreto. Pero la tributación a los comerciantes se hizo efectiva de algún modo, pues era la principal fuente de ingresos de la capital del estado soberano. La Cámara Provincial tenía facultades para imponer tributos a las casas comerciales y a los pasajeros que cruzaran su territorio, las cuales no se usaron temporalmente por las amenazas de invasión de William Walker, un filibustero que se había tomado a Nicaragua, y por los eventos que condujeron a la toma de Texas. En 1854 estalló la Guerra de la Sandía que generó una asonada contra los norteamericanos en tránsito y cobró la vida de 15 de ellos y de dos panameños, la cual se zanjó abonando US\$412.000 al gobierno de Estados Unidos (Araúz y Pizzurno, 1993, 161 y 162).

En 1871, el presupuesto de ingresos del estado soberano muestra una concentración muy grande en la capital y en el Distrito de $\mathrm{Pa}$ namá (cuadro 9), que generaba el 58\% de los ingresos, Colón, con el 10,4\%, y Coclé y Chiriquí, con un poco más del 7,7\% cada uno. Los Santos recaudaba el 8,6\% y Veraguas el 6,2\%. En el distrito capital, la contribución de los comerciantes era mayoritaria, el 34\% del ingreso presupuestado, seguida por la subvención del ferrocarril, \$25.000 -un 16\%-, mientras que el impuesto de degüello al ganado aportaba el 16,3\% y el de cría el 3\%. Ambos gravaban fuertemente el consumo de carne y limitaron el acceso de los más pobres a este alimento. Considerando los gastos presupuestados, en 1871 se registró un déficit cuantioso, de unos $\$ 51.000$, y el orden de preferencia es el siguiente.

Los gastos generales (cuadro 10) representan un 13\%, el servicio de la deuda un porcentaje similar, las obras públicas un $12 \%$, la fuerza pública un $28,3 \%$-el gasto más importante-, y la instrucción un $4,4 \%$, que refleja los intereses de las masas urbanas que lograron representación política y asignaron recursos a la educación, aunque todavía era una partida muy insuficiente. Los rubros de la sección primera parecen estar asociados a los gastos del distrito capital y los de la sección segunda al resto del territorio. 
Cuadro 9

Contribuciones presupuestales, capital y Departamento de Panamá, 1871 (Pesos y porcentaje)

\begin{tabular}{lrr}
\hline \multicolumn{1}{c}{ Rubro } & & \\
\hline Contribución comercios & 53.400 & 34,2 \\
Pecuaria de cría & 4.512 & 2,9 \\
Pecuaria de consumo & 25.428 & 16,3 \\
Urbana & 11.347 & 7,3 \\
Aguardiente & 3.177 & 2,0 \\
Papel sellado & 5.000 & 3,2 \\
Subtotal & 118.259 & \\
Renta bienes del estado & 10.000 & 6,4 \\
Subvención del ferrocarril & 25.000 & 16,0 \\
Aprovechamientos & 3.000 & 1,9 \\
Subtotal & 38.000 & \\
Subtotal distrito capital & 156.259 & 58,0 \\
Otras provincias & & \\
Coclé & 20.772 & 7,7 \\
Colón & 28.047 & 10,4 \\
Chiriquí & 20.458 & 7,6 \\
Los Santos & 23.037 & 8,6 \\
Veraguas & 16.658 & 6,2 \\
Gran total & 269.261 & \\
\hline Fut Leyes de Panas & & \\
& &
\end{tabular}

Fuente: Leyes de Panamá, 1870.

Cuadro 10

Gastos presupuestados por el estado soberano de Panamá, 1871 (Pesos y porcentaje)

\begin{tabular}{llrrr}
\hline Rubro & & & & \\
\hline Generales & 42.607 & & 13,2 \\
& Asamblea & & 8.000 & \\
& Presidencia & & 10.357 & \\
& Justicia & & 16.963 & \\
Deuda & Hacienda & & 8.408 & \\
Obras públicas & & 42.967 & & 13,4 \\
Fuerza pública & & 38.440 & & 11,9 \\
Instrucción pública & & 91.000 & & 28,3 \\
Otros & 14.080 & & 4,4 \\
Sección primera & & & & \\
Sección segunda & & 257.245 & & \\
& & 64.596 & & \\
\hline
\end{tabular}

Fuente: Leyes de Panamá, 1870.

En 1880 (cuadro 11) los ingresos presupuestados (\$300.628) fueron inferiores a los de la década anterior (\$321.841). E1 distrito capital aportó casi el 60\% del total y Colón fue superado por Los Santos. E1 ferrocarril representó un 14\% de los ingresos del distrito capital, la 
contribución de comercio fue mayoritaria, con un 48\%, y los impuestos a la ganadería de cría y de consumo aportaron el $30 \%$ de los ingresos. En términos de progresividad podemos suponer que la contribución del comercio más la urbana, que debía ser equivalente a un impuesto predial, sumaban el $57 \%$ del recaudo, mientras que un $5 \%$ de los gravámenes recaía sobre las transacciones y escrituras (papel sellado y registro de documentos).

Cuadro 11

Contribuciones presupuestales capital y Departamento de Panamá, 1880 (Pesos y porcentaje)

\begin{tabular}{lrr}
\hline & Aporte & \\
\hline Contribución comercios & 65.000 & 48,3 \\
Pecuaria de cría & 3.300 & 2,4 \\
Pecuaria de consumo & 38.000 & 28,2 \\
Urbana & 12.000 & 8,9 \\
Contribuciones incorporadas & 2.000 & 1,5 \\
Papel sellado & 4.000 & 3,0 \\
Registro de documentos & 2.400 & 1,8 \\
Correos & 1.000 & 0,7 \\
Vendutas & 1.000 & 0,7 \\
Agencias de vapores & 6.000 & 4,2 \\
Subtotal & 134.700 & \\
Renta bienes del estado & 10.000 & 5,7 \\
Subvención del ferrocarril & 25.000 & 14,1 \\
Aprovechamientos & 6.000 & 3,4 \\
Subtotal & 41.000 & \\
Total & 176.700 & 58,8 \\
Coclé & 20.820 & 6,9 \\
Colón & 22.885 & 7,6 \\
Chiriquí & 16.968 & 5,6 \\
Los Santos & 23.845 & 7,9 \\
Veraguas & 17.545 & 5,8 \\
Gran total & 300.628 & 100,0 \\
\hline
\end{tabular}

Fuente: Leyes de Panamá, 1879.

En los gastos presupuestados la fuerza pública sigue dominando con cerca del 18\%, la deuda es un 13\%, la participación de la educación se ha duplicado (de $\$ 14.000$ a $\$ 28.000$ ), el 9,3\%, mostrando de nuevo que la participación política del arrabal lograba asignar recursos cada vez más importantes al gasto social.

Para el estado soberano tenemos datos más o menos completos de los presupuestos y su estructura entre 1854 y 1860 porque en el resto del periodo solo figura por aparte Ciudad de Panamá, y las demás provincias están agregadas. El impuesto mayoritario recae sobre el consumo de carne, lo que indica una carga tributaria muy elevada a este alimento y que la distribución del ingreso se deteriora después 
de impuestos. E1 segundo rubro es el tributo al comercio, y no se sabe bien si recae sobre las transacciones internacionales, sobre las ventas internas o si es una combinación de ambas.

Cuadro 12

Gastos presupuestados por el estado soberano de Panamá, 1880

(Pesos y porcentaje)

\begin{tabular}{llrrr}
\hline Rubro & & & & \\
\hline Generales & Asamblea & 37.233 & 7.933 & 12,3 \\
& Presidencia & & 7.600 & \\
& Justicia & & 19.952 & \\
& Hacienda & & 20.939 & \\
Deuda & & 39.000 & & 12,9 \\
Obras públicas & & 32.388 & & 10,7 \\
Beneficencia & 5.540 & 2,2 \\
Fuerza pública & 54.384 & & 17,9 \\
Instrucción pública & 28.295 & & 9,3 \\
& & 238.731 & & \\
Sección primera & & 64.296 & & \\
Sección segunda & & & & \\
& & 303.027 & \\
Total gastos & & & \\
\hline
\end{tabular}

Fuente: Leyes de Panamá, 1879.

Para Ciudad de Panamá, la serie comienza en 1860 y en su estructura predomina el impuesto al comercio, aunque pierde alguna importancia desde 1870. Otro rubro importante es el oneroso impuesto al degüello que recauda entre el 20 y el 30\% de los ingresos de la ciudad. Sigue el impuesto a la renta de la propiedad raíz con cerca del 10\% del recaudo. $\mathrm{El}$ ingreso del ferrocarril, por lo general $\$ 25.000$, representa entre un $16 \%$ y un $10 \%$ del recaudo.

Al comienzo, cuando los ingresos del estado soberano eran pequeños, entre un 30 y un 50\% del gasto mantenía el funcionamiento del gobierno: la asamblea, la presidencia, la justicia y la secretaría de hacienda (gráfica 8). De 1865 en adelante, cuando mejoraron los ingresos, este rubro solo representaba entre el 10 y el $20 \%$ del gasto presupuestado. El gasto más importante durante los 30 años considerados fue el de la fuerza pública, que por lo común superaba el $20 \%$ y en varios periodos fue superior al $30 \%$, a pesar de las quejas de que la guardia era demasiado pequeña y no garantizaba la seguridad de los comerciantes ni de los pasajeros que atravesaban el istmo. Los comerciantes norteamericanos organizaron entonces una guardia 
privada e impusieron cuotas, al tiempo que se negaron a pagar los impuestos que, como se vio, ocupaban el primer lugar de los ingresos del Estado. A menudo también desembarcaba la tropa apostada en los barcos que Estados Unidos mantenía en la ensenada de Panamá.

Gráfica 6

Estructura de ingresos del estado soberano de Panamá, 1856-1860

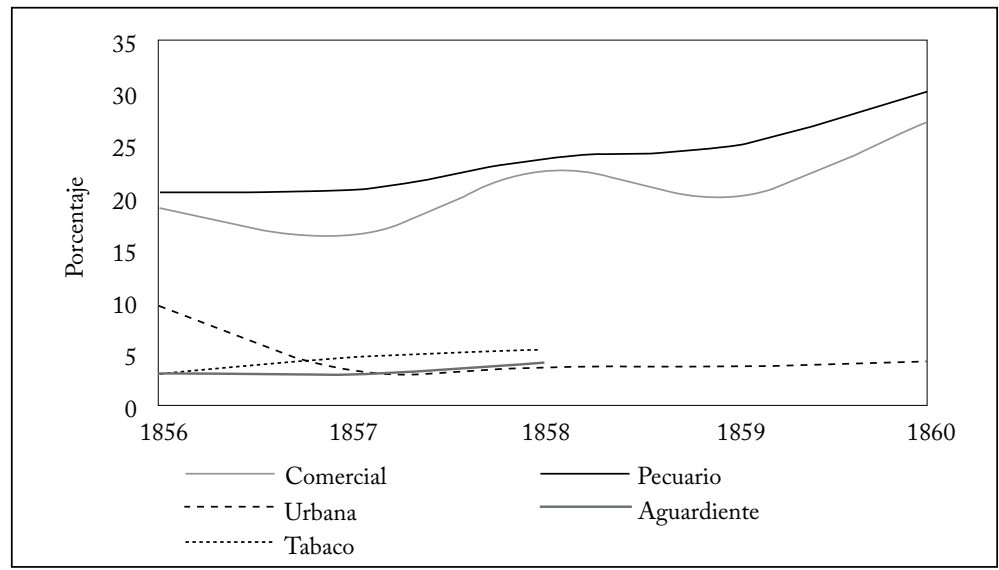

Fuente: Leyes de Panamá.

Gráfica 7

Estructura de ingresos de Ciudad de Panamá, 1860-1885

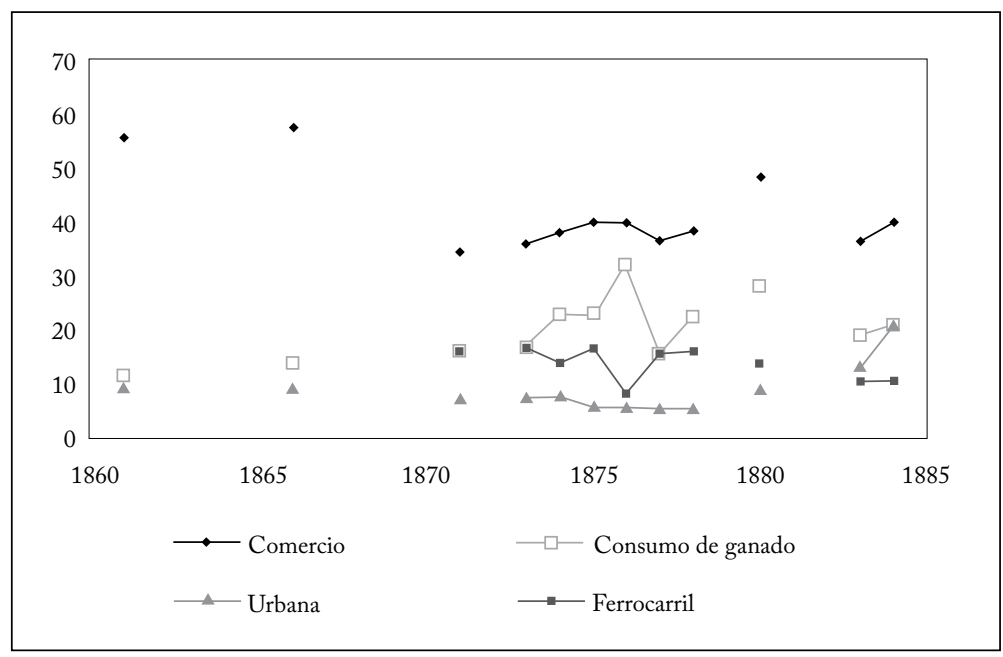

Fuente: Leyes de Panamá. 
Gráfica 8

Estructura de gastos del estado soberano de Panamá

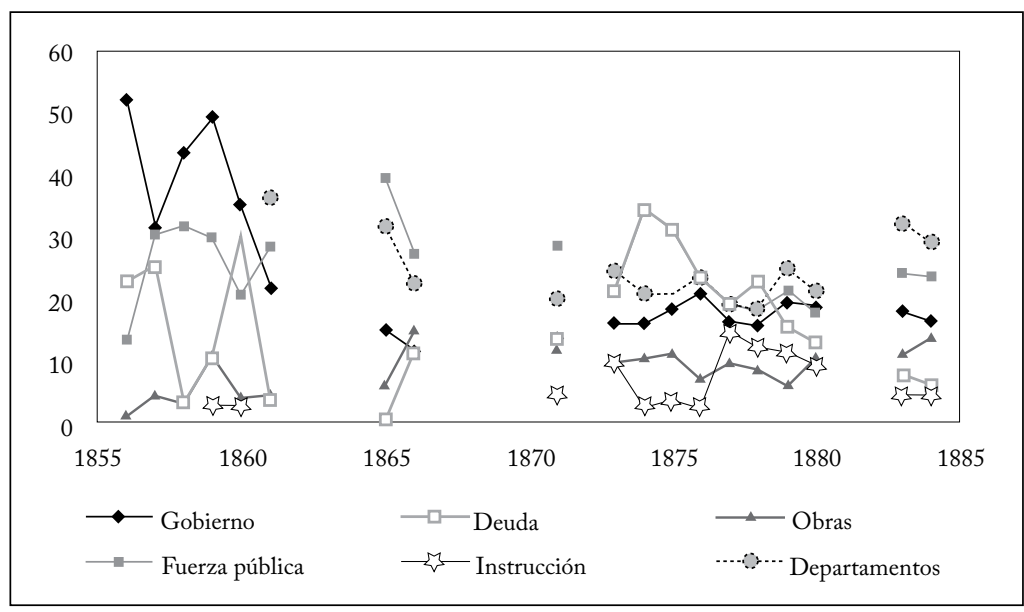

Fuente: Leyes de Panamá.

La instrucción pública no figura en la mayor parte de los informes de presupuesto de la secretaría de hacienda, pero aparece en 1862 con el $4 \%$ del gasto y con el $12 \%$ al final del periodo considerado. El progreso es notorio pues luego de una total despreocupación de los gobiernos del estado soberano por la educación, ganó presencia en 1860 y con mayor continuidad y volumen de recursos en la década de los setenta.

En 1872 se creó la primera Escuela Normal de Varones de Panamá, que funcionó durante 15 años [...] Esta escuela se creó en virtud de la ley que el presidente Eustorgio Salgar logró que expidiera el Congreso Nacional autorizando la creación de escuelas normales en las capitales de departamento. La misma fue de gran trascendencia para la educación y la vida istmeña [...] En esta segunda mitad del siglo XIX se notó el incremento de escuelas primarias, tanto en la capital como en el interior del país. En varios lugares se establecieron escuelas de adultos. Este proceso $[\ldots]$ se paralizó previa a la separación [...] ya que se cerraron los planteles de enseñanza y el sistema educativo se paralizó a consecuencia de la pérdida de autonomía del istmo y de la Guerra de los Mil Días (Céspedes, 1985).

A pesar del impulso educativo, Panamá registraba un índice de educación primaria como porcentaje de la población inferior al de Colombia, que fuera uno de los países más atrasados del mundo en materia educativa durante el siglo XIX (Ramírez, Salazar, 2010, 420). Las niñas no alcanzan a ser un $25 \%$ del total enrolado y el índice total es muy bajo y volátil.

En comparación con los demás estados de la confederación, el recaudo por habitante de Panamá fue el más elevado en 1851 y en 
1870. Le seguían en importancia Bolívar y Antioquia. Pero estamos hablando de $\$ 1,30$ contra $\$ 0,95$, y frente a un ingreso por habitante de unos $\$ 33$ en 1870 , solo llega al 3\%.

Cuadro 13

Alumnos en primaria, en Panamá y Colombia, 1835-1894

\begin{tabular}{lcccc}
\hline & Alumnos & Población & Panamá \% & Colombia \% \\
\hline 1835 & 573 & 97.683 & 1,6 & 1,4 \\
1976 & 1.976 & 100.844 & 2,0 & 3,8 \\
1848 & 1.433 & 115.303 & 1,2 & 1,9 \\
1874 & 1.065 & 205.971 & 0,5 & 3,1 \\
1894 & 3.407 & 288.307 & 1,2 & 2,2 \\
\hline
\end{tabular}

Fuente: Ramírez y Salazar (2010, 453).

Gráfica 9

Ingreso fiscal comparado por habitante

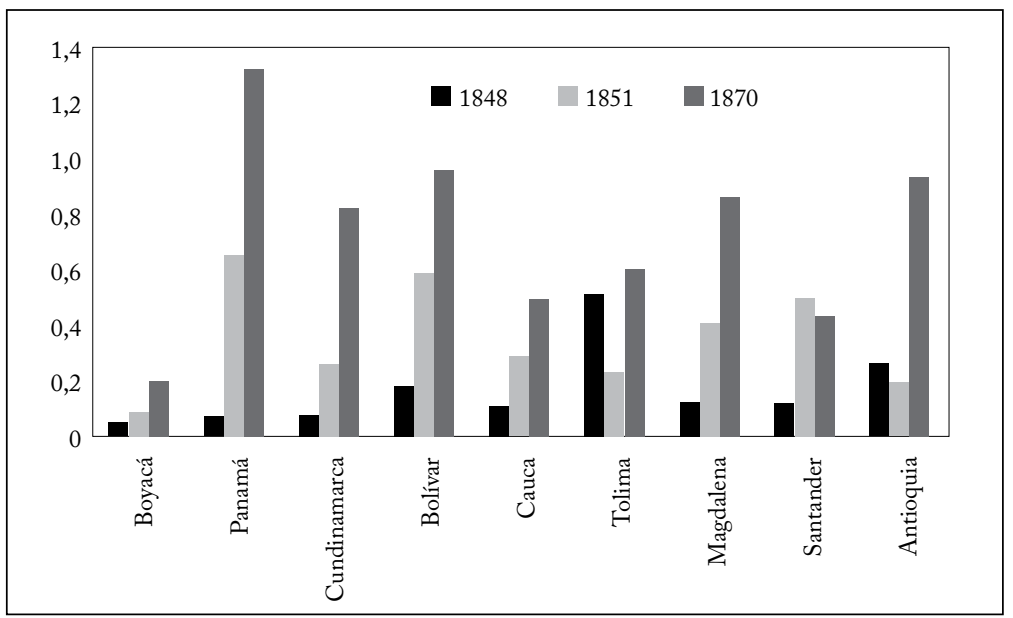

Fuente: Kalmanovitz y López (2010).

En términos de recaudo total, los estados soberanos de mayor población, Cundinamarca y Antioquia, recaudaron en promedio $\$ 350.000$ entre 1848 y 1872 (gráfica 10), seguidos por Cauca y, no muy lejos, por Panamá, a pesar de tener una menor población que los demás estados soberanos.

En 1888 el periódico liberal La Idea denunció “que el régimen conservador había disminuido el status del istmo [...] le había arrebatado el 10\% de la anualidad del ferrocarril -que le había sido concedido en el contrato firmado entre el gobierno colombiano y la empresa norteamericana en 1867-, había cerrado sus escuelas y le había quitado su autonomía" (Aparicio, 2004b, 244). Surgieron además "conflictos 
relativos al sistema de puertos libres, la política monetaria y la reforma del sistema fiscal. Además la creación de monopolios nacionales, la imposición de 'préstamos forzosos'y el incremento de los impuestos exacerbaron estos sentimientos de insatisfacción” (ibíd., 245).

Gráfica 10

Recaudo promedio de los estados federales, 1848-1872

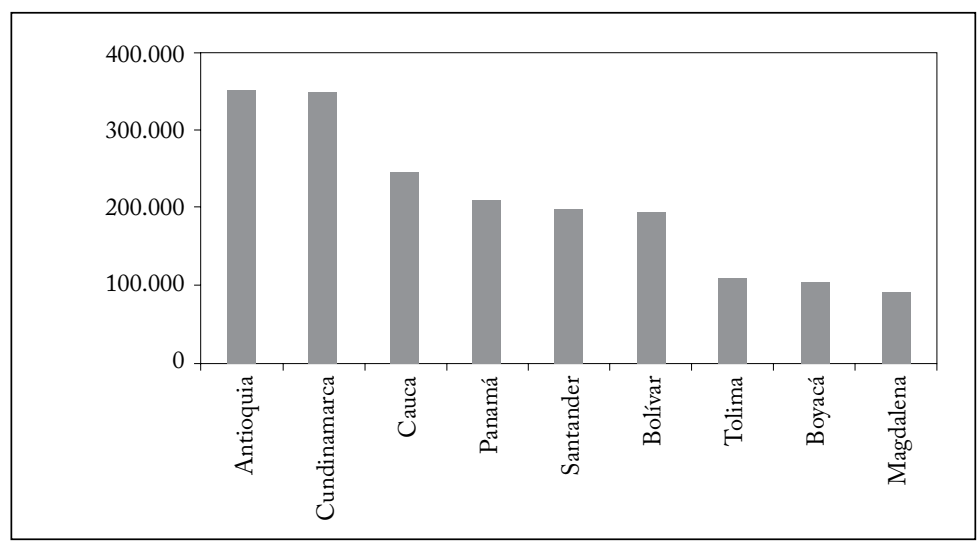

Fuente: Kalmanovitz y López (2010).

\section{CONCLUSIÓNY EPÍLOGO}

Panamá siempre estuvo en una posición incómoda frente al centro político colombiano, posición que mejoró cuando los liberales lograron impulsar y consolidar un Estado federal. La posición se tornó insostenible cuando los conservadores impusieron su visión de un Estado centralista, clerical y proteccionista que impedía lograr las metas políticas y económicas que se planteó la élite panameña como su razón de ser, aprovechando su dotación geográfica.

La política monetaria que acompañó al curso forzoso del papel moneda que se emitía de manera creciente y que produjo una inflación incremental fue rechazada por los comerciantes panameños que preferían transar en divisas internacionales y no en un papel moneda que contenía un impuesto inflacionario y que añadía incertidumbre a las transacciones internacionales, imposibilitando los créditos y letras a mediano plazo. Así mismo, el papel moneda inflacionario causó una caída de la actividad comercial, el cierre de varios bancos y perjudicó, en especial, a los exportadores que recibían una moneda cada vez más desvalorizada a cambio de sus ingresos externos en moneda fuerte. En términos nominales, la tasa de cambio de 1903 fue 90 veces más 
alta que la de 1880; en la gráfica 11 se usó una escala semilogarítmica para reducir la enorme dispersión.

Gráfica 11

Tasa de cambio de Colombia, 1870-1910

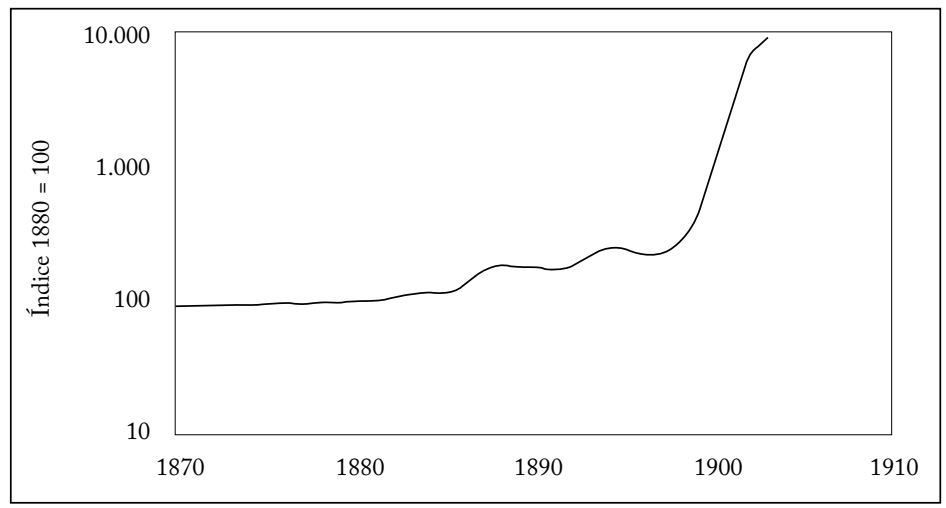

Fuente: Ocampo (1984, cuadro 4.2).

E1 gobierno nacional duplicó las tasas impositivas de las casas comerciales, de la propiedad urbana, del consumo de res y del registro civil (Aparicio, 2004b, 248). En 1894, el impuesto que se cobraba a las casas comerciales por sus ventas pasó a ser un arancel que recaía sobre sus importaciones y se extendió a los ingresos de las casas de cambio, los bancos, las empresas de vapores y los hoteles. El impuesto a la propiedad también pasó de ser parte del flujo generado por el inmueble a derivarse del valor de la propiedad. Las actividades de los mataderos, que eran una renta local, pasaron a ser una renta nacional y sus tasas se duplicaron. Los préstamos forzosos se multiplicaron, ahora exigidos por el gobierno nacional, cuyo monto si acaso devolvía se veía reducido sustancialmente por la inflación. Al mismo, tiempo el gasto público ejecutado en Panamá seguía siendo irrisorio. Así, el gobierno central se transformó en un ente depredador que succionaba la savia comercial y productiva del istmo: en vez de lubricar el desarrollo económico, lo frenaba brutalmente.

La gráfica 12 muestra el ingreso fiscal de Panamá en el más largo plazo y permite establecer un claro contraste entre la época federal (1856-1880) y la de la centralización conservadora (1880-1902): la primera de tributación relativamente consensuada, decidida a nivel local, y la segunda de exacción arbitraria de impuestos por parte del gobierno central. Una vez convertido en departamento, la exacción de 
impuestos a Panamá aumentó en un 140\%, aunque la contabilidad se vuelve un ejercicio formal en el que se repite el mismo presupuesto de rentas y gastos durante dos y hasta tres años, resultando perfectamente equilibrado. Sin embargo, la inflación erosionó el monto de las rentas. Utilizamos la tasa de cambio de Colombia, representada por la letra de cambio a tres meses vendida en Bogotá, como proxy de la inflación, lo que es especialmente pertinente para Panamá, una economía abierta. Cuando la inflación llegó al 300 o 400\% anual, como ocurrió de 1900 en adelante, las rentas públicas del departamento quedaron trituradas, reducidas a su mínimo histórico.

Gráfica 12

Rentas reales de Panamá, 1856-1900

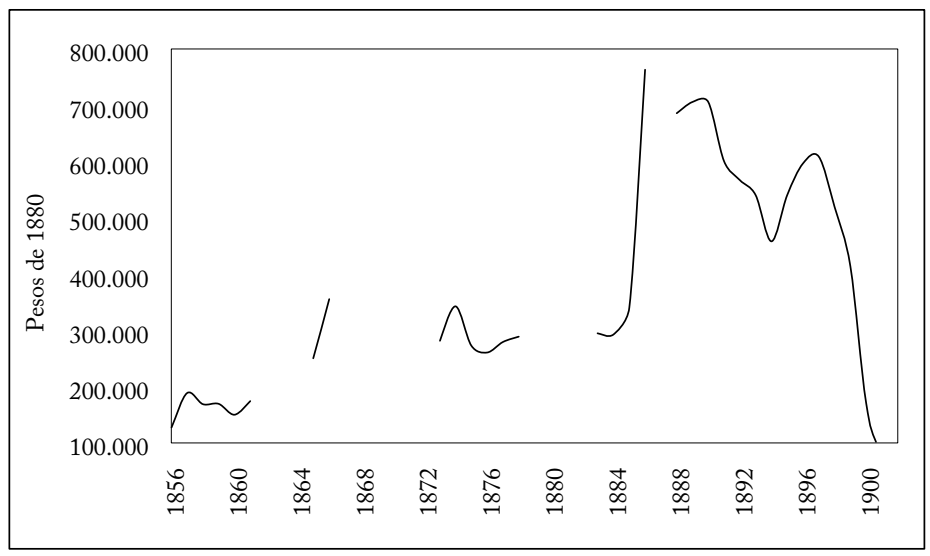

Fuente: Datos propios y Ng (1972), deflactada por tasa de cambio $1880=100$.

Las concesiones logradas por las masas y defendidas por algunos caudillos liberales fueron derogadas por La Regeneración. La represión de los intereses de las élites y de los sectores populares llevó a que Panamá fuera epicentro de resistencia armada durante las guerras civiles de 1895 y de 1899-1902. E1 fracaso de La Regeneración en su relación con el istmo fue ostensible y se deterioró hasta el punto de no retorno: "la propia represión entre 1885 y 1899 no hizo más que servir de caldo de cultivo para la más violenta, extensa e intensa de las guerras civiles [...] la Guerra de los Mil Días. Habría que buscarse también en esta política represiva, la reacción anti colombiana que reanimó la nacionalidad panameña y que condujo al movimiento separatista de 1903" (Aparicio, 2004b, 245). 
La población partió de una base muy pequeña, con una composición similar a la del resto de Colombia, aunque creció menos que la de los estados soberanos caribeños a principios del siglo XIX, y recibió importantes corrientes migratorias cuando se construyó el ferrocarril y después el canal. La geografía panameña tampoco fue amable para el desarrollo agropecuario, pero, a medida que se poblaba el occidente del estado soberano y después República de Panamá, en las regiones más salubres fueron surgiendo hatos productivos y plantaciones de café, banano y otros alimentos que aumentaron la riqueza producida en su territorio.

Las cuentas fiscales muestran una región sumamente pobre cuya riqueza va aumentando con el tránsito de bienes y personas que atraviesan el istmo en sus diferentes momentos históricos y valoriza las propiedades y los comercios, y aumenta también el recaudo tributario. Este será volátil, reflejo de los avatares de auge y colapso de los medios utilizados en la travesía entre el Pacífico y el Atlántico. La hipótesis que se plantea es que el ingreso por habitante de Panamá debió ser bastante superior al promedio de los Estados Unidos de Colombia en 1870, aunque después se deterioró visiblemente, lo mismo que en la República de Colombia con La Regeneración, por el deterioro de los términos de intercambio que causó la crisis global de la década final del siglo XIX. El ingreso fiscal se sostenía en los impuestos al comercio y el consumo de carne; el canon por el ferrocarril apareció en los años setenta y también fue importante. El gasto iba sobre todo a seguridad, con una ausencia de fondos para educación que se iniciaron en la década de los setenta y luego crecieron debido a la participación política de las clases subordinadas.

Los norteamericanos terminaron el canal en 1914, once años después de la separación de Colombia, y la zona del canal fue sustraída a la economía panameña, formando un enclave de ingresos similares a los del Sur de Estados Unidos, con pocos vasos comunicantes con el resto del territorio. El sistema de "comisariato" monopolizó los servicios de apoyo para el funcionamiento del canal e hizo imposible que los empresarios panameños compitieran, pues lo excluyó de las compras. La malla alrededor de la zona prohibía la entrada de nacionales y quienes lograban trabajar dentro de ella eran tratados como ciudadanos de segunda clase (Maurer y Yu, 2011, 322). La zona admitía bienes sin arancel y se atribuía el derecho de venderlos en Panamá (McKay, 2004). El país permaneció en una pobreza relativa, aunque los norteamericanos combatieron las enfermedades endémicas y así beneficiaron a todos los habitantes del istmo. La pobreza se 
atenuó con el desarrollo agropecuario en regiones como Chiriquí y Bocas del Toro durante el siglo XX. El canal se devolvió a Panamá, después de que Jimmy Carter logró que el Senado aprobara en 1978 dos tratados que permitían devolverlo a sus dueños. En 1999 pasó a la soberanía panameña, lo que integró la economía canalera al resto del territorio, aceleró su crecimiento económico y la convirtió en centro financiero donde se pagan muy pocos impuestos que atrae población de altos ingresos, de América Latina y de Estados Unidos, que forman enclaves dentro de la economía panameña.

Gráfica 13

PIB por habitante, Panamá y Colombia, 1950-2010

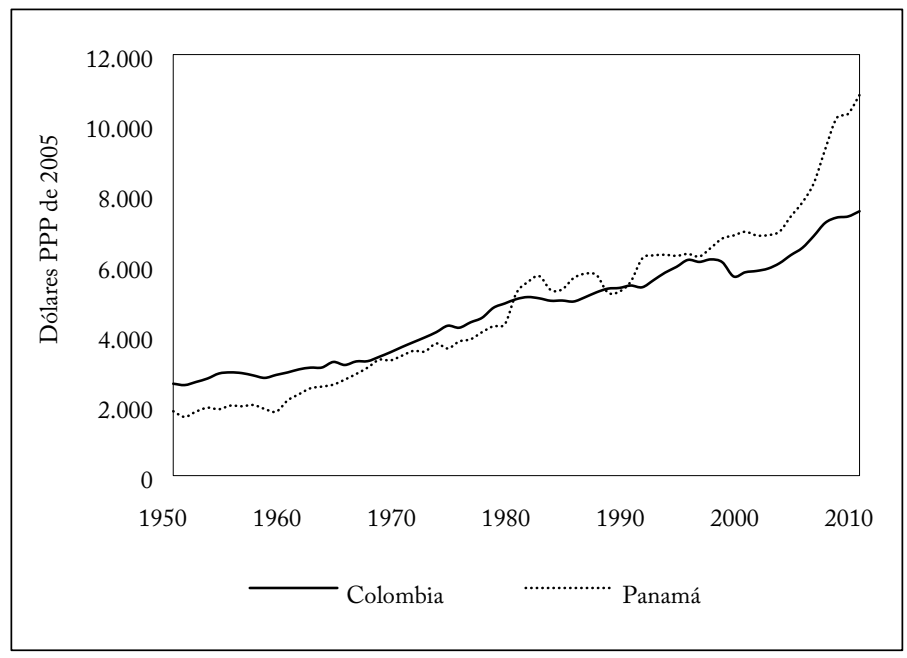

Fuente: Heston et al. (2012).

La comparación entre el ingreso por habitante de Panamá y Colombia durante el siglo XX muestra que hubo cierta convergencia (gráfica 13), pero que Panamá tiende a superar a Colombia; con la ampliación del canal emprendida en 2010 aumenta la brecha a favor de los istmeños en un 35\%. Panamá no sufrió inflaciones altas como las que sufrió Colombia entre 1903 y 2010 ni enfrentó crisis cambiarias por utilizar el dólar como moneda. Entre otras cosas, la hiperinflación colombiana que acompañó a la guerra de los mil días fue una experiencia muy dolorosa para Panamá y fue un factor clave en su decisión de adoptar el dólar como moneda.

Adolfo Meisel argumenta que Panamá hizo bien en retirarse de Colombia porque si hubiese permanecido dentro de la República 
habría recibido un trato discriminatorio, como la región Caribe y el Chocó, y que su PIB por habitante sería similar al de las regiones más pobres de Colombia (Meisel, 2008). Esto ya remite a argumentos contrafactuales difíciles de evaluar rigurosamente. En todo caso, si Colombia hubiese mantenido a Panamá dentro de sus límites geográficos y hubiera construido el canal, el ingreso del istmo sería más alto que el del Caribe colombiano; como lo fue en 1870 como resultado del tráfico comercial y de su prosperidad agropecuaria. En todo caso, eso es campo de conjeturas y prefiero cerrar aquí el ensayo sobre el federalismo y las cuentas fiscales del Estados Soberano de Panamá, esperando haber demostrado que fue una región rica y que recaudó más impuestos que los demás estados soberanos de Colombia.

\section{ANEXO 1}

Distritos gravados con empréstito forzoso, Departamento de Fábrega, 1862 (Pesos)

\begin{tabular}{lc}
\hline Distrito & Cantidad \\
\hline Atalaya & 500 \\
Calobre & 405 \\
Cañazas & 450 \\
Herrera & 790 \\
La Mesa & 160 \\
Las Palmas & 950 \\
Ponuga & 200 \\
Río de Jesús & 700 \\
San Francisco & 1.010 \\
Santiago & 475 \\
Soná & 1.270 \\
Total & 6.910 \\
\hline
\end{tabular}

Personas gravadas con empréstito forzoso, Departamento de Fábrega, 1862 (Pesos)

\begin{tabular}{lclc}
\hline Personas & Cantidad & Personas & Cantidad \\
\hline Francisco de Fábrega & 1000 & Evaristo Tejada & 100 \\
José Fábrega Barrera & 500 & Juan Isabel Victoria & 100 \\
José Fábrega & 500 & Cecilio Victoria & 100 \\
Eustacio Fábrega & 500 & Manuel Osorio & 100 \\
Manuel de la Guardia A. & 500 & Manuel González & 100 \\
Nicolás García & 200 & Juan B. Fuentes & 80 \\
José Manuel López & 100 & Felipe Ruiloba & 60 \\
Antonio Tejeira & 100 & Dámaso Robles & 40 \\
Demetrio Valdez & 100 & Rosa Fuentes & 30 \\
José María Barrera & 15 & & \\
Manuel A. González & 15 & & 740 \\
Total & 3.500 & Total & \\
\hline
\end{tabular}

Fuente: Préstamos forzosos, Kam (Apuntes, s.f.b).

\section{ANEXO 2}




\section{METODOLOGÍA - APÉNDiCE DE DATOS}

Para conseguir la información sobre ingresos y gastos del estado soberano de $\mathrm{Pa}$ namá se revisaron los informes de secretarios de hacienda y los diferentes números de la Gaceta Oficial del Estado, pero en dichas fuentes no se encontraron datos. La información sobre Panamá en el periodo federal es escasa, por ello se optó por tomar los presupuestos que se encuentran en las leyes expedidas como variable proxy de su balance fiscal. Se tomaron los datos desde 1856 hasta 1884, que incluye el periodo anterior a la Constitución de Rionegro (con la cual se inició el régimen federal), hasta comienzos de La Regeneración que volvió al centralismo.

El artículo 952 del Código Administrativo del Estado Soberano de Panamá determina que el presidente del Estado debe elaborar un presupuesto anual mediante un proyecto de ley, el cual debe presentar a la asamblea legislativa para su aprobación. Ese documento estaría compuesto por un presupuesto de rentas y un presupuesto de gastos. Por el lado de los ingresos, se presentaban las rentas desagregadas por municipios año tras año, lo que permite estimar el ingreso total del estado soberano. Entre las principales rentas del periodo se encuentran las contribuciones de comercios, rentas urbanas, por actividad pecuaria, tabaco, destilación de aguardiente y papel sellado:

- La contribución comercial aportaba la mayor parte de los ingresos y gravaba almacenes y tiendas, locales y extranjeras (exceptuando las nacionales que solo vendían tabaco o aguardiente), casas de consignación, casas de banco, compañías de navegación, vendutas, farmacias, posadas y otros.

- La contribución urbana era un impuesto que gravaba todas las propiedades de particulares (casas, fincas y otras). El monto dependía del tipo de propiedad, por ejemplo, en el caso de una finca productora de algún bien, se tomaban en cuenta las rentas que generaba.

- La contribución pecuaria de cría gravaba el ganado (vacas, mulas y caballos) que se tuviese en una propiedad. El ganadero debía reportar anualmente el número de sus cabezas de ganado para liquidar el monto que debía pagar.

- La contribución pecuaria de consumo gravaba el ganado destinado al consumo (vacas, cerdos, cabras y ovejas). Solo afectaba el ganado destinado a una transacción comercial, no se cobraba impuesto al sacrificio para consumo privado.

- E1 impuesto sobre la destilación de aguardiente era el primer paso para adquirir un permiso o licencia del recaudador fiscal del distrito, el administrador departamental y el agente fiscal del distrito correspondiente, para realizar dicha actividad durante un año. Al pasar ese tiempo, se debía pagar nuevamente el impuesto y solicitar las licencias correspondientes.

- El impuesto de papel sellado era un pago por hoja de papel que el gobierno hacía timbrar conforme a la ley establecida. Los escritos judiciales o escrituras son ejemplos de documentos que debían timbrarse.

E1 presupuesto de gastos, según el artículo 957 del Código Administrativo de Panamá, debía dividirse en siete departamentos: gobierno, justicia, hacienda, deuda del estado, beneficencia, obras públicas y fuerza pública.

- El departamento de gobierno se encargaba de los gastos relacionados con el personal y el material de los poderes legislativo y ejecutivo, además de los gastos causados por medidas administrativas.

- El departamento de justicia era el encargado de los gastos de personal y material de la corte superior, de los juzgados y del ministerio público. 
- El departamento de hacienda debía encargarse de los gastos causados por el personal y material de las oficinas fiscales, los gastos relacionados con bienes del estado y, en general, todo lo que abarca el manejo del tesoro.

- En el departamento de deuda, sus principales gastos eran la emisión y amortización de vales, así como la liquidación y pago de intereses.

- El departamento de beneficencia debía encargarse del pago de recompensas y reconocimientos que diese el estado, y de los recursos destinados a instrucción y caridad.

- E1 departamento de obras públicas se encargaba de lo relacionado con la construcción y mantenimientos de obras públicas ejecutadas por el estado.

- E1 departamento de fuerza pública generaba gastos por todo lo relacionado con la milicia del estado.

\section{FUENTES}

- Código administrativo de Panamá

- Constitución y leyes de 1865

- Constitución y leyes expedidas por la Asamblea Constituyente del Estado de Panamá en 1855: precedidas de los actos legislativos y ejecutivos nacionales relativos a su creación

- Leyes expedidas por la Asamblea Legislativa del Estado Soberano de Panamá en sus sesiones de 1856

- Leyes expedidas por la Asamblea Legislativa del Estado Soberano de Panamá en sus sesiones de 1857

- Leyes expedidas por la Asamblea Legislativa del Estado Soberano de Panamá en sus sesiones de 1858

- Leyes expedidas por la Asamblea Legislativa del Estado Soberano de Panamá en sus sesiones de 1859

- Leyes expedidas por la Asamblea Legislativa del Estado Soberano de Panamá en sus sesiones de 1860

- Leyes expedidas por la Asamblea Legislativa del Estado Soberano de Panamá en sus sesiones de 1866

- Leyes expedidas por la Asamblea Legislativa del Estado Soberano de Panamá en sus sesiones de 1870

- Leyes de Panamá (presupuestos de 1871 a 1876)

- Leyes expedidas por la Asamblea Legislativa del Estado Soberano de Panamá en sus sesiones de 1877-1878

- Leyes expedidas por la Asamblea Legislativa del Estado Soberano de Panamá en sus sesiones de 1878-1879

- Leyes expedidas por la Asamblea Legislativa del Estado Soberano de Panamá en sus sesiones de 1879-1880

- Leyes expedidas por la Asamblea Legislativa del Estado Soberano de Panamá en sus sesiones de 1880-1881

- Leyes expedidas por la Asamblea Legislativa del Estado Soberano de Panamá en sus sesiones de 1882

\section{REFERENCIAS BIBLIOGRÁFICAS}


1. Alarcón, O. Panamá, capital de Colombia, Bogotá, Politécnico Grancolombiano, 2010.

2. Aparicio, F. "Federalismo e inestabilidad. Panamá bajo la Constitución de Río Negro”, A. Castillero, dir., Historia extensa de Panamá, vol. 2, Ciudad de Panamá, Comité Nacional del Centenario, 2004a.

3. Aparicio, F. "Represión y explotación en Panamá durante La Regeneración: 1886-1903”, A. Castillero, Historia extensa de Panamá, vol. 2, Ciudad de Panamá, Comité Nacional del Centenario, 2004b.

4. Araúz, C. y P. Pizzurno. "E1 Panamá hispano (1501-1821)”, La Prensa, Panamá, 1991.

5. Araúz, C. y P. Pizzurno. "E1 Panamá colombiano (1821-1903)”, Panamá, Primer Banco de Ahorros y La Prensa, 1993.

6. Arosemena, J. Fundación de la nacionalidad panameña, Caracas, Biblioteca Ayacucho, 1982.

7. Bergquist, Ch. Café y conflicto en Colombia. 1886-1910, Medellín, FAES, 1981.

8. Bonilla, H. y G. Montañez, eds. Colombia y Panamá, Bogotá, Universidad Nacional de Colombia, 2004.

9. Castillero, A., dir. y ed. Historia extensa de Panamá, Ciudad de Panamá, Comité Nacional del Centenario de Panamá, 2004.

10. Castillero, A. "Ciclos y coyunturas en la economía panameña", segunda parte, Ciudad de Panamá, Tareas 120, 2005.

11. Castillero, A. Cultura alimentaria y globalización, Panamá, siglo XVI a XXI, Ciudad de Panamá, Editora Nova Art, 2010.

12. Cavelier, G. Centenario de Panamá, Bogotá, Universidad Externado de Colombia, 2003.

13. Céspedes, F. La educación en Panamá, Biblioteca de la Cultura Panameña, t. 4, Ciudad de Panamá, Imprenta de la Universidad de Panamá, 1985.

14. Correa, J. S. "E1 ferrocarril de Panamá y la pérdida de una nación”, Credencial Historia 256, 2011a.

15. Correa, J. S. "Colombia y la Doctrina Monroe: el caso del Ferrocarril de Panamá y las intervenciones estadounidenses en el istmo”, Santa Marta, Primer Congreso de Historia Económica del Caribe, 2011b.

16. Díaz E., O. How Wall Street created a Nation, New York, Four Walls Eight Windows, 2001.

17. Figueroa N., A. Dominio y sociedad en el Panamá colombiano, 1871-1903, Bogotá, Tercer Mundo, 1978.

18. Fischer, Th. "Antes de la separación de Panamá: la Guerra de los Mil Días, el contexto internacional y el Canal”, Anuario Colombiano de Historia, 1998.

19. Flórez, C. E. y O. L. Romero. "La demografía de Colombia en el siglo XIX”, Meisel, A. y Ramírez, M. T. Economía colombiana del siglo XIX, Bogotá, Fondo de Cultura Económica, 2010.

20. Heston, A.; R. Summers y B. Aten. Penn World Table Version 7.1, Center for International Comparisons of Production, Income and Prices at the University of Pennsylvania, July 12, 2012.

21. Hinestrosa, F. "A Panamá no nos la quitaron, la perdió el abandono de Colombia”, Revista de Economía Institucional 6, 10, 2004, pp. 223-227.

22. Jaén, O. La población del istmo de Panamá, Ciudad de Panamá, Impresora de la Nación, 1979. 
23. Jaén, O.; C. Alvarado; C. A. Vargas y A. J. Adames. El Canal de Panamá, Cuidad de Panamá, Ediciones Balboa, 1999.

24. Kalmanovitz, S. y E. López. Las cuentas nacionales de Colombia en el siglo XIX, Bogotá, Universidad Jorge Tadeo Lozano, 2009.

25. Kalmanovitz, S. y E. López. "Las finanzas públicas de la Confederación Granadina y los Estados Unidos de Colombia, 1850-1886”, Revista de Economia Institucional 12, 23, 2010, pp. 199-228.

26. Kam R., J. "Antecedentes históricos para el estudio del Estado Federal de Panamá”, Ciudad de Panamá, Biblioteca Nacional de Panamá, s.f.a.

27. Kam R., J. "Apuntes sobre legislación del Estado Federal de Panamá, 1855-1863”, Ciudad de Panamá, Biblioteca Nacional de Panamá, s.f.b.

28. Lemaitre, E. Panamá y su separación de Colombia, Bogotá, Intermedio, 2003.

29. Martínez F., A. "Bargaining for fiscal control: Tax federalism in Brazil and Mexico, 1870-1940”, México, D.F., Banco de México, 2011.

30. Martínez G., A. "La acción de los liberales panameños en la determinación de las políticas del Estado de la Nueva Granada, 1848-1855", Bonilla, H. y G. Montañez, eds. Colombia y Panamá, Bogotá, Universidad Nacional de Colombia, 2004.

31. Maurer, N. y C. Yu. The Big Ditch, Princeton, Princeton University Press, 2011.

32. McKay, A. "El canal, los puertos, movimientos e industrias marítimas", Castillero, A., dir. y ed. Historia extensa de Panamá, vol. III, t. II , Ciudad de Panamá, Comité Nacional del Centenario de Panamá, 2004.

33. McCullough, D. The path between the seas: The creation of the Panama Canal 1870-1914, New York, Simon and Schuster, 1977.

34. Meisel, A. El Espectador, columna del 11 de julio de 2008.

35. $\mathrm{Ng}, \mathrm{L}$. "Los presupuestos de rentas y gastos del estado soberano de Panamá", Panamá, Universidad de Panamá, 1972.

36. Nugent, J. y J. Robinson. "Are factor endowments fate?", Revista de Historia Económica 28, 2010, pp. 45-82.

37. Poveda R., G. "La construcción del ferrocarril de Panamá”, Dyna 143, 2004, pp. 1-12.

38. Randall, S. Aliados y distantes: las relaciones entre Colombia desde la Independencia hasta la guerra contra las drogas, Bogotá, Uniandes, 1992.

39. Santos M., E. [1903] Adiós Panamá, Bogotá, Villegas Editores, 2004.

40. Sosa, J. B. Compendio de historia de Panamá, 1911, [http://www.banrepcultural.org/blaavirtual/historia/hispa/hispa05e.htm].

41. Vega, R.; S. Jaúregui y L. C. Ortiz. El Panamá colombiano en la repartición imperialista, Bogotá, Alejandría Libros, 2003. 